\title{
Filling the Gaps: Vacancy Chains and Agent-Based Models
}

Radu Andrei Pârvulescu*

January $11^{\text {th }}, 2022$

\begin{abstract}
This paper introduces a demographic agent-based model of mobility in opportunity structures featuring vacancy chains, such as jobs in bureaucracies or homes in residential housing systems. The novel computational treatment of vacancy dynamics is superior to analytic variants by enabling us to 1) model off-equilibrium situations; 2) simulate multiple, overlapping, exogenous shocks of varying duration and intensity; 3) instantiate dynamic systems with an inherent tendency towards stability; 4) refine theory through pattern-oriented modelling; 5) increase realism by relaxing standard Markovian assumptions of embeddedness, homogeneity, and stationarity; and 6) generate confidence bands for point estimates. Parametrising these computational vacancy models with empirical data on professional mobility among judges in a postrevolutionary context reveals an unexpected career mechanism, the purge boomerang. Meta-theoretically, this paper furthers computational ABMs by introducing a model that explicitly codes vacancies as agents, a formalisation of absence akin to the zero symbol in arithmetic.
\end{abstract}

keywords: opportunity structure, mobility, vacancy chains, agent-based models

\section{Introduction ${ }^{\dagger}$}

Mobility in hierarchical organisations, housing scenes, and even used car markets is usually preceded by a vacancy: one cannot get promoted to a higher position, move into a new house, or buy a secondhand car unless the former occupant has left, creating an opening. At the system level, the introduction of a vacancy generates a vacancy chain: with bureaucratic jobs, for instance, whenever a person moves to fill a vacant position, their old spot becomes open, allowing someone else to fill it, thereby shifting the vacancy onto their old position, and so on until a new worker is recruited from the outside. Vacancy chains are pervasive in opportunity structures characterised by closed positions, defined as social resources (such as jobs or houses) which are only vacated at the current occupant's discretion. Barring gross incompetence or brilliant office politics, one cannot be promoted to a desired position until the incumbent has left, often due their own promotion or retirement. Vacancy chain analysis (VCA)

* Radu Andrei Pârvulescu is a recent graduate of the Department of Sociology at Cornell University, and currently works for the Canadian Housing Statistics Program at Statistics Canada. Email: rap348@cornell.edu.

$\dagger \quad$ For feedback on earlier versions of this paper I would like to thank participants at the European Sociological Association Research Network-21 (Quantitative Methods) Online Conference on October 8-10, 2020, as well as graduate students and faculty attending a presentation in the department of sociology of Cornell University on October $7^{\text {th }}$, 2020. Data collection on the pre-revolutionary career trajectories of Romanian judges was supported by a grant from Cornell University's Center for the Study of Society and Economy. Many, many thanks to Maria and Catherine Nonna Pârvulescu for their keen eye and unwavering support. 
explains mobility in systems of closed positions, which are an exclusivist and constrained opportunity structures, in contrast to the free-for-all bidding wars of neoclassical markets.

The bulk of this article is spent justifying and developing a new class of computational models for studying vacancy dynamics. I begin by presenting the realist relational theory of social positions that underwrites vacancy chains analysis. The second section reviews the still-canonical, analytic, Markovian formalism of VCA, including related models that stand to gain from improvements in VCA techniques. Section three introduces the White-Chase-Sørensen (WCS) model, the computational ABM of vacancy processes at the heart of this paper; a full ODD protocol of the model (Grimm et al. 2006, 2010, 2020) is left for Appendix 1. Section four illustrates the WCS model's operation using both toy data and empirical estimates of professional mobility among judges. Here we see that that WCS models both replicate closed-form results and open new possibilities for VCA, in particular by: 1) modelling off-equilibrium situations; 2) simulating multiple, overlapping, exogenous shocks of varying duration and intensity, such as social revolutions; 3) instantiating dynamic systems with an inherent tendency towards stability, for example prototypical bureaucracies; 4) refining theory through pattern-oriented modelling; 5) increasing realism by relaxing standard Markovian assumptions of embeddedness, homogeneity, and stationarity; and 6) generating confidence bands for point estimates. The empirical study also unearths a hitherto untheorised, demographic mechanism of organisational mobility, the purge boomerang.

The final section reviews limitations in the WCS model and points to further refinements, notably modelling the vacancy filling process as tournaments (Lazear and Rosen 1981) and endogenising system size by giving positions life courses. It concludes with a reflection on the advantages to agent-based modelling of formally representing absences, in this case vacancies.

\section{Theoretical Foundations}

\section{Tenure as Real Relationship}

The formal theory of vacancy chains begins with Harrison White's Chains of Opportunity (1970), which develops a suite of Markov models for tracing the sequential openings of clergy positions in three US churches. ${ }^{1}$ Chains of Opportunity presumes that people and positions are duals (White 1970:1), a reference to the mathematical concepts whereby one structure is mapped onto another in a one-to-one fashion. ${ }^{2}$ In social contexts this duality implies that an occupant and her position in social space are mutually constituted by virtue of their relationship: White calls this occupant-position relationship a "tenure". To give a trivial example, a queen rules when enthroned and the throne carries authority when hosting a queen. ${ }^{3}$ Ontologically, thrones turn regular people into monarchs and monarchs turn fancy chairs into thrones. Such occupant-position relationships of co-constitution are causal, and therefore real, ${ }^{4}$ which justifies using changes in tenure (such as a vacancy) to detect

1 Vacancy chain analysis was first elaborated in housing research (e.g. Kristof 1965), perhaps because vacant lots and empty homes are directly observable and intuitively meaningful. White addressed housing markets in a 1971 article (White 1971) that was sufficiently important to draw a rebuttal over a decade later (Marullo 1985).

2 See more in the Wikipedia article on duality: https://en.wikipedia.org/wiki/Duality (mathematics)

3 That this view of duality is indeed that of White is confirmed by his student Ronald Breiger's famous article on personnetwork duality (Breiger 1974), which was published shortly after Chains of Opportunity.

4 The causal criterion of existence - "things are real if they can affect other things"-(cf. Porpora 2015:168-75) is trivial for tangible objects that can be perceived, but crucial for intangibles that can only be detected, such as magnetic waves or suicidal thoughts. In such cases we ascribe reality to unseen forces inasmuch as they tend to cause needles to point north and people to kill themselves. I say "tend" because the causal entity in question might be probabilistic, as with radioactive decay (Cartwright 1989:105-12), or retarded by other factors, as Durkheim famously claimed that familial 
dynamics in causally linked structures, much as one infers a rocky riverbed when looking at white water rapids. ${ }^{5}$ This concept of person-position duality and the relational realism of tenures theoretically licenses all VCA research.

Further theoretical elaboration can be found in Aage B. Sørensen (1983), ${ }^{6}$ which tethers tenure in vacancy chain systems to the Weberian concept of the closed relationships. In Weber's view, relational closure occurs when at least one party has a right to a relationship with the other side(s): for instance, spousal affection, or having a debtor. Sørensen extends this closed/open framework to positions $^{7}$ such that a position is closed when its occupant has rights or possession over it. ${ }^{8}$ The main causal implication of positional closure is that tenure acts a barrier to entry. Queens leave the throne through death or abdication: the difficulty of forcing them out proves the position's closure. Thus, tenure is defined as an occupant-position relationship that makes it easy for occupants to stay put and hard for pretenders to get in. An occupant, on the other hand, is defined as an individual in a position.

What then is a vacancy? Nothing more than tenure by an absence. Both persons and positions can have constitutive ties with an absence. A widow is not merely someone without a spouse (that is, single), but someone whose spouse has died. Likewise, an empty ecological niche is not just an unoccupied position, like a crater on the moon, but a space in the food chain that could sustain a species. ${ }^{9,10}$ In both cases the occupants and positions are defined by a relationship to an absence. A vacancy is therefore defined not simply as an absence, but as an absence tied to a closed position: this is what distinguishes a lengthy interregnum from a republic. Finally, vacancies are constitutive and causal, both because vacant positions attract occupants much like a social vacuum and because overlong vacancies destroy: thrones reverts to fancy chairs unless periodically occupied by monarchs.

To sum, the duality of occupants and positions means that tenures are real relationships that occur in the context of closed positions. Furthermore, tenure tends to bind occupants to their position, while it tends to kick vacancies out by attracting new occupants. Next, we explore how these causal tendencies shape social competition.

\section{Vacancy Competition and Closed Position Systems}

Not all relational structures enable positional closure and causal tenures, so we must define the structural context of vacancy chains. Equating positions with resource units, Ivan Chase posits that tenures only occur only when "the resource units in question are reusable, discrete, identifiable, and utilised by one individual or social group at a time," that "a unit must be vacant before it can be taken by a new occupant" and that "individuals must need or want new and usually "bigger" or "better" units from time to time.” Moreover, "vacant units must be scarce...[i.e.] small compared to the number of

ties depress suicide.

5 I owe this imagery to Vogel (1996:256-57)

6 Harrison White suggests that he had such things in mind in White (1971:89).

7 Note the relational, proto-network approach in Sørensen (1983:206) as well: "Positions are nodes in social relationships and are defined by these relationships."

8 The converse, of positions having rights or possession over persons, has not been explicitly touched in VCA. This is unfortunate, because "duties of office” (of which captains going down with their ships are but one, dramatic example) are a necessary condition for bureaucracy (Weber 1978); and bureaucracy is the primary site of VCA research.

9 Abbott has explicitly used the vacancy chain metaphor to explore movement in and out of niches an ecology of professions (Abbott 1988:88-89).

10 Andrew Collier calls the loss of an essential quality (as in widowhood; he uses the example of a tree turned into coal by a forest fire, thereby losing its life) "absenting," while he refers to ecological niches (such as one presumably opened in New Zealand by the lack of land mammals) "real absences.” In both cases the absence is real, though differing in kind (Collier 2001:304). 
individuals who want them," "most individuals in a group must already have units so they can leave one behind when they move to a new one,” and finally "the number of recruits [must be] relatively small compared to the number of individuals already in the system." (Chase 1991:135-36). ${ }^{11}$ These conditions form the scope of vacancy chain analysis. We can now turn to competition.

Recall the barrier to entry erected by occupying a closed positions: Sørensen contrasts this to the open positions of neoclassical markets, in which someone fulfilling a certain task can always be kicked out by a lower bidder. Consequently, Sørensen provides two ideal types of regimes of competition situated at opposing ends of a spectrum: systems of open and closed positions. ${ }^{12}$ Acquiring positions in open systems is a matter of competitive exchange in the framework of neoclassic markets. Closed position systems, on the other hand, feature vacancy competition, which first means that openings only occur when an incumbent leaves a position and terminates a tenure, through force or free will but not usually by being outbid. This dependence on vacancy timing combines with the fact that (a) knowledge about, and (b) eligibility to vacant positions are often highly circumscribed. This combination severely constrain the candidate pool, so candidate selection for open positions typically involves a tournament between a small set of individuals (Lazear and Rosen 1981; Rosenbaum 1979).

The operation of vacancy competition entails a particular causal mechanism that both empties and fills closed positions: the vacancy chain. An especially clear example is the death of a queen, in which case everyone in line for the throne moves up one spot. To be exact, each time a royal moves up one step the absence introduced by the queen's death moves down a rung. Such parallel movement of occupants and vacancies also occurs in job and and housing systems when filling an empty job or house after a retirement or departure. In all cases, once an absence is introduced the particular type of competition in the closed position system-usually a tournament-does the rest. By assumption, positions higher up are in sufficient demand that tournament-successful incumbents lower down always vacate their old positions, thereby shifting the vacancy down and occasioning another tournament, and so on all the way down, where an incumbent from outside the system is recruited. ${ }^{13}$ In other words, the introduction of a vacancy and the nature of competition in closed position systems are enough to induce vacancy chains.

Generally speaking, VCA cannot answer why people compete: it is assumed that they do, and shows how this competitive orientation is funnelled by the structure of closed position systems. ${ }^{14}$ Substantively interpretation, however, requires accounting for that competitive orientation. In most instances, personal desire for advancement combined with a relative lack of opportunities (Friman 2004) will be enough to stimulate competition. In other cases vacancy competition may be induced by non-volitional factors, such as standard operating principles applied in loosely coupled organisations (Vogel 1996:247-53). Explaining the source of the competitive orientation is not necessary for applying the VCA method, but it is crucial for interpreting the results.

This theoretical section has grounded VCA in intuitive, commonsensical notions of realism and relationality: throughout this paper I use the terms "tenure," “occupant," and "vacancy” in an everyday manner. Rigorously defining common sense concepts is helpful down the road because formal VCA models can quickly become counter-intuitive and confusing: we are, after all, trying to measure the

11 I took this particular of condensing Chase's definition from Friman (2004:55).

12 Chase calls closed position systems "vacancy chain systems.” I prefer Sorensen's terminology because a) it connect the theory to Weber, b) it encourages an analytic distinction between positional closure and vacancy competition, and c) it highlights that positional closure is logically prior to the vacancy tie (closed positions need not be vacant, but vacancies require closed positions), and by extension closed positions are prior to vacancy chains.

13 In some medieval contexts (and in many medieval novels) recruitment into the nobility occured via a literal tournament.

14 Exogenising the reasons for competition renders vacancy competition a poorer concept than other variants of structureconditioned competition. For example, Smith Marx, and Winters (2011:20-26) all base their versions of market, capitalist, and oligarchic on a generalised fear of losing one's livelihood to competitors. 
causal movement of absences in an intangible social space. The next section introduces this VCA formalism.

\section{Analytic, Markov Models of Vacancy Chain Analysis}

Analytic, Markov vacancy-chain analysis, or AM-VCA, was introduced in Chains of Opportunity to study job changes among US protestant clergy. ${ }^{15}$ As a state transition model, AM-VCA requires a mutually exclusive and jointly exhaustive set of states between which movement can occur. These states are usually hierarchical levels, which may already exist (as bureaucratic pay grades) or can inferred, such as proxying the pay and prestige of clergy positions by the size of the hiring parish (White 1970:76-91).

Next, we must specify all possible inter-state transition probabilities, for vacancies. In the literature, these probabilities are estimated from two types of data. The simpler data source lets us count the actual movement of vacancies and derive the associated probabilities. For example, consulting yearly announcements of clergy retirements, transferrals, and so on reveals where and when vacancies entered the diocesan job system and how these vacancies moved about. More commonly, however, we only have access to yearly incumbent lists identifying who is located where. Therefore, vacancy mobility is usually inferred from occupant mobility, a straightforward task because in a closed position system occupants and vacancies necessarily swap positions. Concretely, this is done by transposing occupant-level transition tables, and turning the counts into probabilities by dividing the cells by their row sums. Tables 1 and 2 illustrate this operation using inter-year mobility rates of Romanian judges for the 2014-2015 period (Pârvulescu 2021). Note that this approach requires knowing the number and hierarchical grade of new recruits to the system.

\begin{tabular}{|l|l|l|l|l|l|}
\hline \multicolumn{5}{|c|}{ Romanian Judiciary, 2014-2015 Transition Frequency Matrix of Judge Moves } \\
\hline From $\downarrow /$ To $\rightarrow$ & High Court & Court of Appeals & County Tribunal & Local Court & Sum \\
\hline High Court & 0 & 1 & 0 & 0 & 1 \\
\hline Court of Appeals & 5 & 3 & 0 & 4 & 12 \\
\hline County Tribunal & 0 & 33 & 25 & 7 & 65 \\
\hline Local Court & 0 & 5 & 79 & 143 & 227 \\
\hline Recruits & 3 & 8 & 16 & 238 & 265 \\
\hline
\end{tabular}

\begin{tabular}{|l|l|l|l|l|l|l|}
\hline \multicolumn{7}{|c|}{ Romanian Judiciary, 2014-2015 Transition Frequency Matrix of Vacancy Moves (transition } \\
probabilities in parentheses) \\
\hline From $\downarrow /$ To $\rightarrow$
\end{tabular}

Tables 1 \& 2: Using a person-level mobility table to infer a vacancy mobility table; *does not sum to one due to rounding

15 Chase (1991) remains the definitive, non-technical, introduction to AM-VCA. 
Armed with the vacancy probability transition matrix we can define a Markov-chain, in particular a discrete, first-order, embedded chain with absorbing states; see Figure 1 for a visual representation. The discreteness assumption is realistic for count data, and the first-order condition presumes that vacancy movement only takes into account the last position, i.e., that vacancies have no memory. Embedding means that we measure chain movement not in real time but in chain steps, and the presence of absorbing states ensures that all chains eventually end. All empirical data on closed position systems violate the latter three assumptions to some extent: published work reports good model fit, despite the approximations. ${ }^{16}$

\section{Markov-Chain State Diagram of Vacancy Mobility in the 2014 Romanian Judiciary}

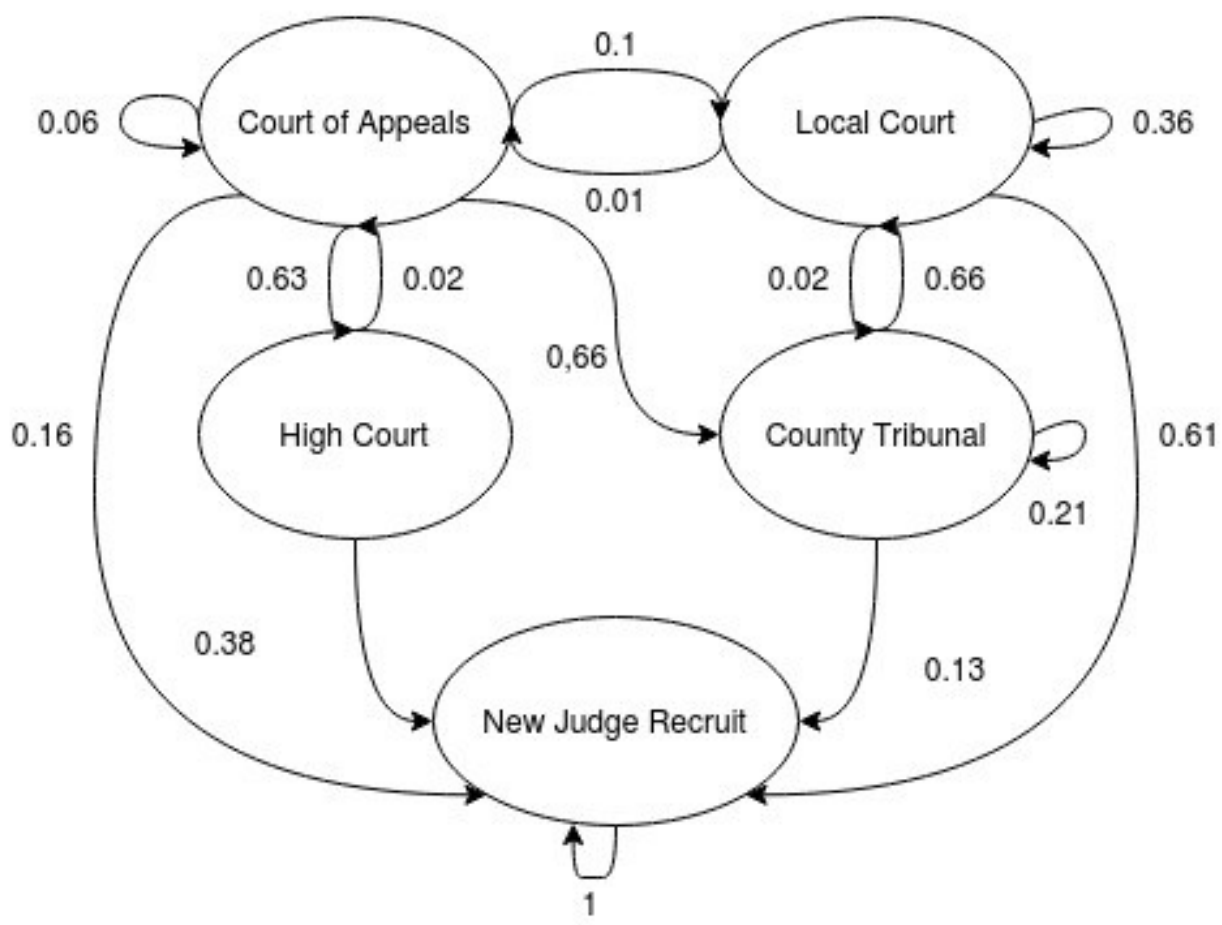

Figure 1: Markov-chain state diagram of vacancy mobility in the 2014 Romanian judiciary

The measures derived from the Markov model relate to the qualities of vacancy chains. One estimate is average chain length, disaggregated by the stratum in which the vacancy enters the system. To illustrate the substantive importance of this measure, consider the claim that building high-end housing ultimately benefit more tenants than building low-income units, since luxury housing stock generates longer average vacancy chains, which pull more families up the housing hierarchy. ${ }^{17}$ AMVCA can also be used to derive the specific number of occupant-level mobility events caused by introducing new vacancies. For instance, we can estimate how many moves will occur among junior managers if their company creates two new executive positions (Chase 1991:143).

Modelling vacancy behaviour using Markov chains, as opposed to simply reporting observed transition counts, has three advantages. First, it is a more realistic model because it incorporates the extreme interdependence of mobility events: no-one can move unless a position opens up. Second, we

16 Model fit is typically assessed along the lines of appendixes B and C in Chains of Opportunity (White 1970).

17 A claim made by White (1971) and contested by Marullo (1985), both using AM-VCA. 
can use a fairly common form of administrative data (incumbent lists, e.g. employment rolls) to detect unseen but important system properties, such as average chain length. Finally, AM-VCA generates comparative statics and therefore counterfactual analysis: how many junior managers would be hired if two more executive positions were to be created? In his review of AM-VCA, Chase (1991) shows how a variety of empirical papers have leveraged these three strengths to contribute to long-standing debates, especially in organisational sociology, housing, and animal ecology.

\section{Related Models}

A number of studies have taken vacancy chains as a starting point and developed related mathematical models: these too would benefit the computational advances introduced below. A first example is Sørensen's family of exponential models, which have been used to estimate the opportunity structure of different groups, such as US whites and blacks (Sørensen 1979). These are built on that assumption that attainment levels (and therefore vacancies) in hierarchies of pay or prestige are exponentially distributed. Abbott and Smith (1984) adapt Markov models of attribute-mediated transitions to estimate whether the succession of occupants in a position is mediated by the occupant's attributes. Concretely, they ask whether recently-departed male coaches of men's and women's university sports teams are more likely to be replaced by male or female coaches. This article addresses the possibility that different positions are "meant for" different kinds of persons, thereby questioning the typical homogeneity assumption of AM-VCA.

A related analytic, Markov-method is the career pathway structure (CPS) model, which Stewman and Yeh (1991) use to study workplace sexual discrimination. This model uses person-level mobility among different units in an organization to estimate an individual's expected lifetime career sequence (e.g. recruit, junior manager, senior manager, executive) before that career actually plays out, much as we compute life expectancy at birth. Yamagata et al. (1997) use CPS models to explore the importance of different organisational pathways in building or breaking glass ceilings for women in the US federal bureaucracy. One of the few strictly theoretical pieces in this tradition, Vogel (1996), leverages VCA to theorise vacancy-mediated mobility system from the ground up, combining deep knowledge of the US criminal justice system with neo-institutionalist organisational theory to conclude that plea bargaining is not primarily meant to reduce a court's backlog of cases but rather to ensure that vacancies in prisons are quickly filled.

In all of these studies the formalism is very similar AM-VCA, thought the objects of analysis are not vacancies as such. Rather, the focus is on the importance of ascribed characteristics, typically race/ethnicity and gender). A computational revitalisation of VCA aims to both incorporate and further such insights.

\section{Limitations of AM-VCA}

Several factors have worked against the broader use of AM-VCA. One substantive weakness of AMVCA has been its failure to endogenise the creation and/or abolition of positions, a key process since the number of positions affects both the number and length vacancy chains. This issue is often swept under the rug by assuming that positions vacant for too long are automatically abolished. ${ }^{18}$ This approach is not unreasonable with regards to job and housing systems, in which positions normally go “off-market” if perennially unoccupied. The converse is also often true: unmet demand for mobility

18 There is also the possibility that some vacancy chains loop (e.g. the vacancy goes from position 1 , to 2 , to 3 , then back to 1 ) which would break the simple Markov model. Such loops are very rare in empirical samples (e.g. White 1970:61,141). 
encourages an increase in vacancies via vacancy creation, as when hierarchical levels are introduced to motivate workers to stay with the firm by giving them additional prospects for promotion. It is a logical step, though one that has not been taken, to allow the size of the system to evolve endogenously.

A host of problems are grounded in the analytic form of the Markov models. First, there is no clear way for AM-VCA to provide confidence measures for point estimates. Second, model fit has often been assessed by comparing predicted and observed chain lengths, a shortcoming because chain length is often unobservable and because there might be other, more relevant patterns against which to measure the model, such as the average cross-level span of a vacancy chain. Third, AM-VCA necessarily assumes that the empirical transition process being modelled is stationary, ${ }^{19}$ which precludes studying dynamics and off-equilibrium systems, for example firms fresh out of a merger. Fourth, positions, vacancies, and occupants are almost always assumed to be homogeneous, a legitimate simplification that in the presence of real heterogeneity buries such differences in a single estimate that averages estimates across groups. Fifth, the assumption of embeddedness, while defensible on grounds of tractability and parsimony, prevents us from studying real-time dynamics, such as the length of (clock) time that it takes for a chain to effect a series of job swaps. ${ }^{20}$

Ultimately, the greatest problem with the analytic, closed-form paradigm has been the difficulty of incorporating other aspects of interest, such as occupant attributes or spin-offs of chain activity (e.g. the cost of each home swap in a housing chain), an issue signalled by (Chase 1991:150). ${ }^{21}$ The next section aims to resolves these issues by introducing a computational approach to the Markovian study of vacancy chains. ${ }^{22}$

\section{The White-Chase-Sørensen Model}

This section introduces a computational, agent-based model for Markov, vacancy chain analysis. The White-Chase-Sørensen (WCS) model is computational in the dual sense that its formal logic is written in computer code and that its results are generated by computer simulation, it is agent-based since endogenous dynamics are driven by interaction between units, it is Markovian as it is a Monte Carlo simulation of Markov chain walks, and it is vacancy chain analysis because it simulates vacancy dynamics in a system of closed positions. ${ }^{23}$

19 Departures from stationarity seem to manifest as poor fit (Stewman 1975:313-18).

20 One could also add that AM-VCA has no home among social science's great meta-theoretical orientations. Game theory encamps with methodological individualism (Porpora 2015 Ch.7, esp. Table 7.1) and network analysis has been grafted onto structural interactionism (Breiger 1974), but where do vacancy chains go? One option would be anti-humanist theory (going from Nietzsche, through Foucault, and into Actor-Network Theory), which contests the centrality of human agency, just as AM-VCA does by highlighting the causal power of vacancies. Continental anti-humanism, however, has always been highly suspicious of formalisation.

21 There have been efforts to keep AM-VCA in tune with the general shift to processual complexity and contingency (e.g. Abbott and Smith 1984; White 1970, Ch.10), but little has come of them.

22 It is doubtful that the underdevelopment of AM-VCA comes down to the difficulty of Markov chain theory. The Markov formalism used by AM-VCA is conceptually simpler than current topics in quantitative graduate seminars, such as instrumental variables, exponential random graphs, or machine-learning. A real hindrance is the lack of plug-andplay statistical software for AM-VCA. The lack of mathematical facility among social scientists is usually papered over by a trial-and-error approach to statistical software, whereby one tells the program what to do, the code somehow fails, and the researcher is forced to think again. Whatever its shortcomings, this folk method of modelling is probably what most quantitative social scientists do, most of the time.

23 I assume that the reader is familiar with broad outlines of computational, agent-based modelling: Macy and Willer (2002) is the now-classic statement in sociology. More recent entry points into the literature on agent-based modeling are (Bianchi and Squazzoni 2015) for sociology, (Hommes and LeBaron 2018) for economics, (de Marchi and Page 2014) for political science, and (Grimm and Railsback 2012) for ecology. As VCA has been applied in all these fields WCS models hold promise for each. Vacancy analysis also originated independently in crystallography and solid-state 
To facilitate a clear introduction and to encourage replication I introduce the WCS model using the ODD protocol (Overview, Deisgn Concepts, and Details) (Grimm et al. 2006, 2010, 2020) which has become the standard idiom for documenting agent/individual-based models in the social and ecological sciences. ${ }^{24}$ For reasons of length I relegate the full protocol to Appendix A and present below a summary ODD, with Figure 2 visually depicting the mechanics of the WCS model. This section introduces the "raw" computational materials, with the "methods" (i.e. the computational experiments) coming immediately after, followed by a brief presentation and discussion of the results. ${ }^{25}$

Summary ODD. A complete, detailed model description, following the ODD (Overview, Design Concepts, Details) protocol (Grimm et al. 2006, 2010, 2020) is provided in Appendix A. The overall purpose of the WCS model is to understand how systems of closed positions respond to exogenous shocks, such as a political purge of high-level office holders. Specifically, I apply the principles and concepts of analytic, Markov, vacancy chain analysis (AM-VCA) in a computational, agent-based setting. To ensure that WCS remains faithful to AM-VCA the former should reproduce three patterns and principles of the latter: vacancies must be approximately time-embedded, cohort effects must be finite, and WCS-derived distributions must eventually converge to closed-form AM-VCA solutions.

The WCS model includes the following entities: actors, vacancies, positions, hierarchical groups of positions, active/retired groups of actors and vacancies, and the global environment. State variables characterising these entities are listed in Tables A1-1 ad A1-2 in Appendix 1. Actors and vacancies can retire or move between positions. ${ }^{26}$ There is no absolute spatial scale in this model, because positions are organised in a hierarchy, whose defining property is that all positions within the same hierarchical level are equally distant both from one another and from positions in other levels. There are, however, three different temporal scales- actor steps, vacancy move periods, and model ticks-which allow actor steps to represent real time units (e.g. years) while approximately time embedding vacancy movement.

The foundational process in this model is the movement of actors and vacancies. At every actor step each actor independently chooses whether or not to retire, and these retirements create a vacancy in the actor's old position. Immediately after the actor step comes the vacancy move period, during which all vacancies in the system move within and between hierarchical levels until each vacancy "retires," thereby recruiting new actors and setting the stage for the next actor step. Our ultimate interest is in how these basic mobility processes interact with changes in system architecture arising either from long, slow trends (e.g. multi-decadal system growth) or sudden shocks (e.g. a sudden purge of high-level actors).

The most important design concept is the way in which the WCS model represents the extreme interdependence of mobility in closed position systems, expressed by the fact that while actors can introduce vacancies, only vacancies can cause actors to move within the system. I therefore allow distributions and dynamics, such as time series of average vacancy chain length, to emerge from the interaction of vacancy mobility and exogenously imposed system changes.

physics, domains further afield.

24 I am particularly indebted to the examples from Supplementary file S1of Grimm et al. (2020).

25 Replication code (using Python's MESA module for agent-based modelling) for the WCS model and computational experiments, as well as the input data, are available at https://github.com/r-parvulescu/abm-vca.

26 While it may seem strange to explicitly code vacancies as agents, conceptually this is no different from the arithmetical use of zero to denote absence, a practice which has proven to be extraordinarily useful and fruitful. 


\section{Simulation Experiments: Illustrating the WCS Model}

\section{A Toy Example of WCS: Replicating and Fulfilling AM-VCA}

The WCS model can both replicate important measures from AM-VCA and generate interesting metrics called for but not actualised by prior work. WCS can replicate AM-VCA because the former is a Monte Carlo simulation of the latter: each vacancy in a WCS model simulates a walk along the Markov chain defined by the underlying vacancy transition probability matrix. ${ }^{27,28}$ Consequently, four tactics increase the resemblance between the mean/first moment of WCS-generated distributions and the closed-form results of AM-VCA: a) increasing system size, and therefore the number of vacancies; b) increasing the number of parallel model iterations across which we average; c) throwing away results from the "burn-in" period immediately following the model's initialisation; and d) increasing the number of post-burn-in actor steps across which we average. In all cases the simulated and analytic results converge because we average over an increasingly large set of stochastic processes, all of which tend towards stationarity since the underlying Markov chain features absorbing states. ${ }^{29}$ Table 3 below shows the key parameters for a toy model used to illustrate how the WCS model can be used to estimate measures of interest to AM-VCA. ${ }^{30}$ Table 4 presents estimates of the means and standard deviations (in parentheses) of distributions of interest to AM-VCA, disaggregated by hierarchical level. ${ }^{31}$

The first measure in Table 4 is vacancy chain length, the sine-qua-non of AM-VCA research. In this case we are able to compare the WCS estimate with the analytic solution: the fit is almost identical, to two decimal points. Next we have estimates of the net benefits arising from vacancy chain mobility, an extension of AC-VCA proposed by Chase (1991:144-46) and applied here for the first time. This measure captures the aggregate benefit accruing from vacancy-chain initiation; for simplicity I use abstract "utility” units. For instance, if we view the toy example as representing families moving through housing units, then the vacancy mobility benefit-deficit matrix in Table 3 depicts a housing market with decreasing marginal utility of housing changes as families move up the housing quality ladder. In other words, moving from low- to mid-level units contributes more to aggregate utility than movement among the upper levels. Such benefit-deficit matrices can also be used to evaluate aggregate third-party benefits from selling housing units, such as realtor commissions or local property-sale taxes. ${ }^{32}$

The next four rows in Table 4 feature estimates of theoretically important distributions which formerly eluded AM-VCA. First we have the length of actor careers, which is one way of measuring

27 It is true that within one model run the vacancies can constrain each other and thereby induce dependence between the walks: see Appendix 1, Submodels, Vacancy Movement. In practice, however, such dependence only matters during a glut of vacancies, for example after a sudden, mass wave of dismissals.

28 While this process is literally a Monte Carlo simulation of Markov chain walks, this is not Markov Chain, Monte Carlo in the statistical/estimation sense off a technique combining a central limit theorem on dependent probability draws with an accept/reject algorithm such as Metropolis-Hastings.

29 We are averaging here in several senses: averaging different walks within one model step, averaging within one model step and then averaging across independent model runs, and finally averaging within one model step and averaging across model runs and averages across steps.

30 I had hoped to replicate results from previous AM-VCA research but unfortunately a key parameter of the WCS model, the retirement rate of actors, was never collected by prior research [Ivan Chase, personal communication].

31 Running one model iteration of the toy example takes roughly forty-two seconds on a 32-bit personal laptop with 4GB of RAM and a two-core processor (without parallel processing).

32 For both the chain length and aggregate benefit measures, "level” indicates the hierarchical stratum at which a chain started. Row three, column two therefore shows the net benefits associated with vacancy chains starting in in level two. 
Figure 2:

schematic

Every model tick during a vacancy move period:

- vacancies move according to transition matrix

- vacancy retirements recruit new actors

\begin{tabular}{|c|c|c|c|c|}
\hline \multicolumn{5}{|c|}{ Vacancy Transition Probability Matrix } \\
\hline $\bar{\sigma}$ & Level 1 & Level 2 & Level $k$ & Retire \\
\hline త్త & $i$ & $i \bar{i}$ & iw & iN \\
\hline$\stackrel{\mathrm{d}}{\mathrm{d}}_{\mathrm{d}}$ N & $v$ & vi & viï & viï \\
\hline$\underset{\mathrm{d}}{\overline{\mathrm{d}}} \star$ & $\dot{\alpha}$ & $x$ & $x i$ & $x \ddot{i}$ \\
\hline
\end{tabular}

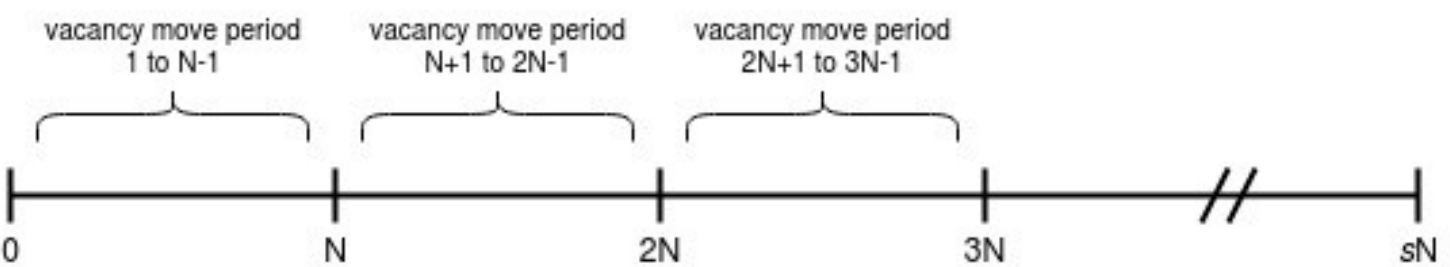

Every $\mathrm{N}^{\text {th }}$ step (i.e. ever actor step):

- collect data generated in previous $\mathrm{N}-1$ model ticks

- actors retire according to per-stratum probability

- actor retirements begin vacancy chains

\begin{tabular}{|c|c|c|}
\hline \multicolumn{3}{|c|}{ Actor Retirement Probabilities } \\
\hline Level 1 & Level 2 & Level $k$ \\
\hline$x$ & $y$ & $z$ \\
\hline
\end{tabular}

representation of the WCS model's process

\section{Parameters of Toy Example}

Number of Model Steps: 3001

Number of Model Iterations: 10
Width of Vacancy Move Period: 30

Number of actor steps: 100

Number of burn-in actor steps: 40

\begin{tabular}{|c|c|c|}
\hline \multicolumn{3}{|c|}{ Number of Actors Per Level } \\
\hline Level 1 & Level 2 & Level 3 \\
\hline 50 & 100 & 150 \\
\hline
\end{tabular}

\begin{tabular}{|c|c|c|}
\hline \multicolumn{3}{|c|}{ Actor Retirement Probabilities } \\
\hline Level 1 & Level 2 & Level 3 \\
\hline 0.1 & 0.075 & 0.05 \\
\hline
\end{tabular}

\begin{tabular}{|c|c|c|c|c|}
\hline \multicolumn{5}{|c|}{ Vacancy Transition Probability Matrix } \\
\hline $\bar{\Phi}$ & Level 1 & Level 2 & Level 3 & Retire \\
\hline دَّ & 0.5 & 0.3 & 0.1 & 0.1 \\
\hline$\Phi_{\bar{\Xi}}^{\bar{\Delta}}$ N & 0.1 & 0.4 & 0.3 & 0.2 \\
\hline ब्ञ & 0.0 & 0.1 & 0.3 & 0.6 \\
\hline
\end{tabular}

\begin{tabular}{|c|c|c|c|c|}
\hline \multicolumn{5}{|c|}{ Vacancy Mobility Benefit-Deficit Matrix } \\
\hline$\Phi$ & Level 1 & Level 2 & Level 3 & Retire \\
\hline ङ & 1 & 2 & 3 & 4 \\
\hline $\bar{\Xi}^{\bar{d}} \mathrm{~N}$ & -1 & 3 & 4 & 5 \\
\hline 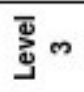 & -2 & -1 & 5 & 6 \\
\hline
\end{tabular}

Table 3: main parameters of a WCS toy model 


\begin{tabular}{|l|l|l|l|}
\hline \multicolumn{4}{|c|}{ Estimates of Measures of Interest to AM-VCA, from Toy Example } \\
\hline Measure $\downarrow$ / Averages (St. Dev.) $\leftrightarrow \rightarrow$ & Level 1 & Level 2 & Level3 \\
\hline Vacancy Chain Length & $4.38(1.23)$ & $3.36(0.85)$ & $1.91(0.6)$ \\
\hline $\begin{array}{l}\text { Markov-chain analytic prediction of } \\
\text { Vacancy Chain Length }\end{array}$ & 4.39 & 3.35 & 1.91 \\
\hline Per-turn Net Benefits of Vacancy Creation & $43.82(22.32)$ & $58.83(26.2)$ & $25.15(16.6)$ \\
\hline Actor Career Length & $14.76(1.16)$ & $12.67(0.77)$ & $9.19(0.59)$ \\
\hline Time to Actor Promotion & & $7.19(2.69)$ & $8.74(2)$ \\
\hline Time to Actor Retirement & $6.95(2.7)$ & $6.84(2.05)$ & $8.94(2.73)$ \\
\hline Per-position rate of actor turnover & $0.05(0.002)$ & $0.04(0.002)$ & $0.03(0.001)$ \\
\hline
\end{tabular}

Table 4: WCS model estimates of measures of interest to AM-VCA

the cumulative experience of actors at different levels: as expected, actors in higher levels tend to be older and more experienced. Next, time to promotion and time to retirement show how long (in actor steps) an actor can expect to wait in a given level before moving up or out. Somewhat surprisingly, in this system the longer waits are in the lowest level, mirroring results from Stewman and Konda (1983). The final row shows an estimate of per-position, per-step actor turnover, that is, in any given actor step how many positions in a certain level are likely to witness a change in the occupying actor. This measure begins answering Chase's call to study the “careers” of resource units, not merely of actors and vacancies (Chase 1991:150).

Figures 5, 6, and 7 confirm that WCS results match theoretically important patterns from AMVCA; the solid lines represent means and the shaded areas represent two standard deviations around the mean line. Figure 5 shows that vacancy chains indeed play out in the vacancy move period between actor steps, thereby instantiating vacancy time-embeddedness. Figure 6 indicates that the cohort effects $^{33}$ on average, per-level actor experience, do not propagate indefinitely and eventually peter out. ${ }^{34}$ Finally, we observe long-run stability in the means of both Figure 6 and Figure 7, the latter referring to average, per-level vacancy chain length. The stable means from Figure 7 approximate the point estimate of vacancy chain length from Table 5, visually confirming the convergence of simulation averages to analytic results. ${ }^{35}$

To sum, the WCS model both replicates and extends AM-VCA theory and practice; four particular contributions stand out. First, we now have confidence regions for parameter estimates. Second, by comparing the WCS-generated time-series to theoretically-informed patterns (namely vacancy embeddedness, finitude of cohort effects, and convergence to analytic results) we have a multifaceted measure of model fit. Third, we are no longer bound to the stationarity assumption, as illustrated by the evolution of the initialisation cohort effect in Figure 6: this frees us to study offequilibrium patterns. Finally, we have successfully endogenised vacancy creation via actor retirement,

33 These dynamics arise because actors must retire after thirty actor steps and all actors are "new” upon initialisation, so the middle "decades" of the model feature a wave of departures as members of the initial cohort retire in close succession.

34 Throwing away burn-in periods reduces this cohort-effect weight on long-run estimates of means from stationary distributions.

35 We cannot confirm whether other distributions, such as average, per-level actor career length, converge onto analytic results because there do not have AM-VCA solutions for these other distributions. Indeed, it is precisely this lack of analytic results that justifies the development of WCS models in the first place. 
which dynamises the WCS model and qualitatively distinguishes it from AM-VCA. The next section illustrates how WCS models can uncover novel theoretical insights and assess empirically-grounded counterfactuals.
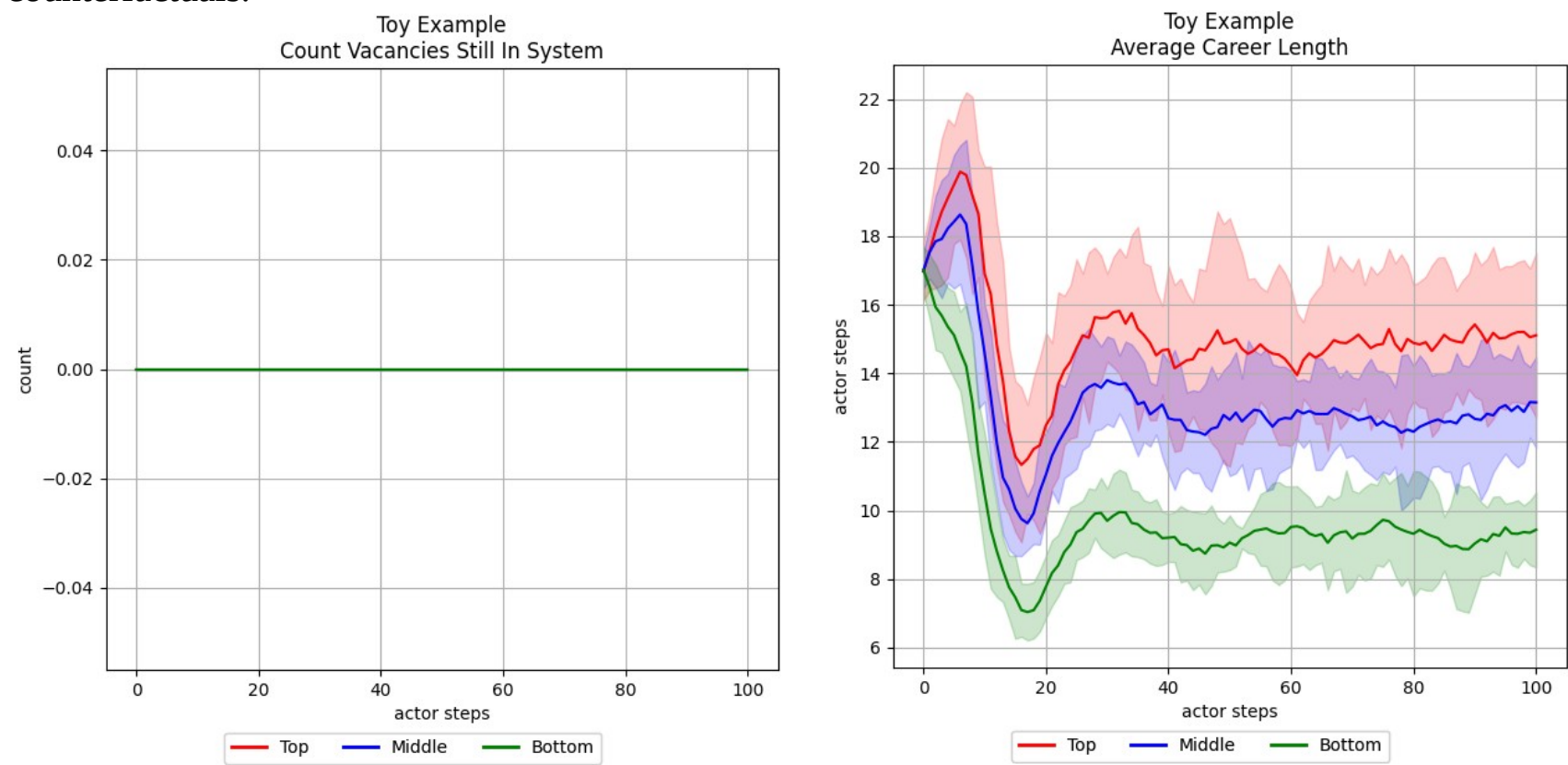

Figure 5: Count of vacancies in system between actor steps

Figure 6: Average actor career length, per level

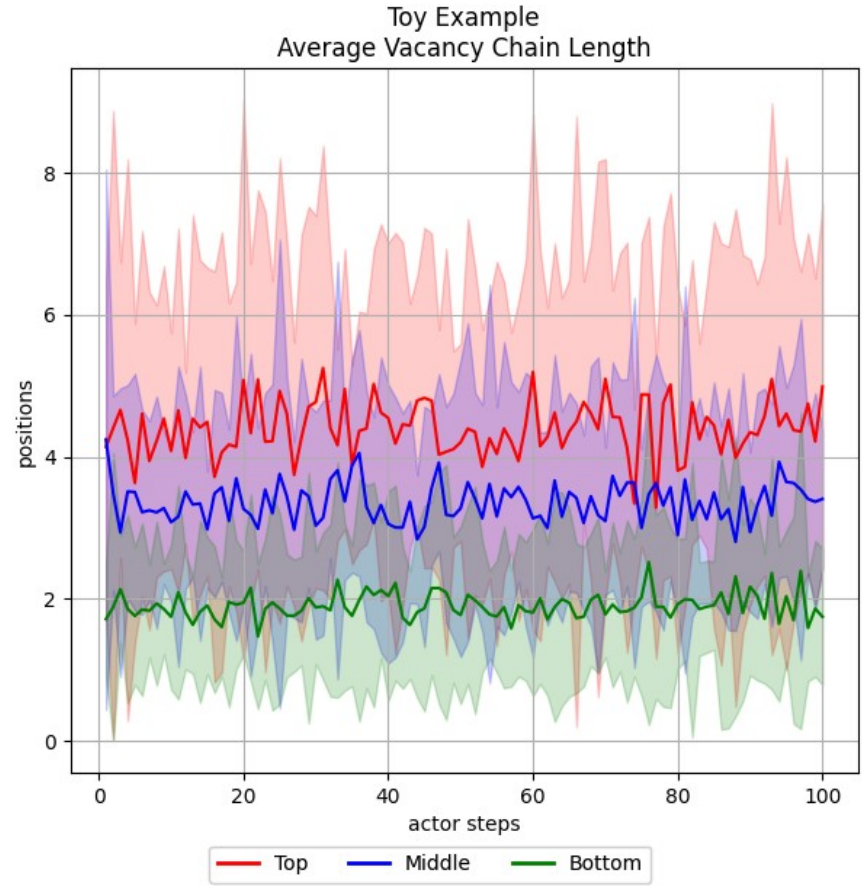

Figure 7: Average vacancy chain length, per level 


\section{An Empirical Illustration: Simulation Experiment of Organisational Mobility During Regime Change}

If the chief purpose of the WCS model is to understand how closed position systems respond to exogenous shocks then there is no better case study than an organisation hit by social revolution. In the following section I therefore use a WCS model to unpack dynamics in the Romanian judiciary from 1985 to 2000, a period in which the national corps of judges was deeply affected by the transition from totalitarian, command-economy socialism to democratic, liberal capitalism. I will not go into the details of the case ${ }^{36}$ focusing on those aspects pertinent to the model. ${ }^{37}$

Revolutions are centrally concerned with law, and revolutionaries do not waste time in reengineering the legal system to actualise their vision of justice. Two oft-used policies in this regard are a purge of the old regime's cadre, especially the erstwhile leadership, and an aggressive recruitment drive, in order to fill newly-vacated positions with sympathisers. This latter is often accompanied by an expansion of the number of positions, putatively to bring justice "closer to the people," but which conveniently creates even more open positions for ambitious recruits As Appendix 2 shows, in the early 1990s the Romanian judiciary experienced all three shocks: a purge at the highest level, a significant drop in the average age of judges as a wave of new recruits entered the system, and precipitous growth in the total number of judges.

This case has two aspects of substantive interest. First, much ink has been spilled on the role of communist-era officials in the new order, on the assumption that the old guard slows down the dual consolidation of democracy and capitalism and should therefore be expunged from public life. In Romania lustration (i.e. purges) of communist decision-makers never took place: a major reason invoked by contemporary policymakers to explain their inaction was that such lustration would lead to crippling de-professionalisation, as too many experienced figures would suddenly bow out to novices (Stan 2012). This argument had the virtue of convenience, because simply waiting would also remove older cadres, albeit at the regular pace of retirement. ${ }^{38}$ The question therefore revolved around the side effects of using lustration to accelerate the normal course of generational turnover.

A second issue regards the drastic feminisation of Romanian judges, which from 1985 to 2005 went from $30 \%$ to over $75 \%$ female across all levels of the judicial hierarchy, including the hundredperson High Court (see Figure 2A-3). Such rapid and thorough feminisation of a top-tier elite professional body is exceedingly rare, though in this case not entirely unexpected since the principal judicial recruitment pool, law-school graduates, had been steadily feminising since at least the late 1970s (see Figure 2A-4). Analytically, we see a long-running cultural tendency (the increasing association of law with women) combining with the aftershocks of a one-time event (the revolution's effects on the judicial profession) to alter the distribution of an attribute (gender) within a population (Romanian judges). All told, the case suggests two sets of counterfactual questions:

a) Would a more forceful policy of lustration (i.e. purging communist judges) have achieved the desired results? And what would have been the effects of this on judicial professionalism?

b) Would the Romanian judiciary have feminised so quickly and thoroughly had socialism continued? How much did the revolution accelerate that already ongoing process?

36 A rigorous history of Romanian judges during either the tail-end of socialism or the early days of capitalism has yet to be written. To date the best references are either on the construction of the socialist legal system (Crăcană 2015), transitional justice widely conceived (Stan 2013), or reflective op-eds by senior judges (e.g.Lupascu [2009]).

37 The replication code for these simulation experiments resides at https://github.com/r-parvulescu/abm-vca.

38 The opposition, of course, retorted that this was hot air from former apparatchiks afraid of losing their perks, including gold-plated pensions for judges who finished their careers in good standing. 
WCS models are well-suited to address these issues. First, while the stationarity and timeembeddedness assumptions may be reasonable of stable, closed position systems, post-revolutionary shocks to the Romanian judiciary featured a destabilising glut of vacancies that could not all be filled in the span of a year; ${ }^{39}$ these assumptions should therefore be relaxed. Second, we can do pattern-oriented modelling (Grimm et al. 2005) with respect to multiple trends of substantive interest, notably the time series of average experience of judges (measured as career length) and the percentage of female judges. We also require entity heterogeneity, in order to model male vs. female judges. Finally, we can address processual complexity by modelling different, super-imposed exogenous changes, each with its own pace: both a one-shot purge and multi-year expansion.

The first step is to parametrise the model using empirical data; see Appendix 3 for parameter values. We then run the simulations and assess fit between the empirical patterns and the output of the WCS model. Since the main goal of this article is to introduce and illustrate a new model I forego a lengthy discussion on the substantive reasons for this particular fit and simply note that the model results in Figure 8 and 9 below (representing dynamics in average career lengths and judicial feminisation from 1990 to 2020) largely mirror the empirical trends in Figures 2A-1 and and 2A-2, albeit at somewhat different scales. Figures 10 and 11 compare baseline and counterfactual models with respect to average career length (i.e. experience) and the speed at which pre-revolutionary judges leave the system. The baseline model, represented by the straight line, simulates observed trends in the Romanian judiciary, such as rapid professional expansion in the 1990s, while the counterfactual model, represented by the dashed line, superimposes a more severe purge/lustration on the system than that which actually occurred in 1990. Finally, Figure 12 shows how the feminisation of the judiciary would have proceeded had the revolution not come in 1990, and the judicial career system of the socialistic 1980s would have kept evolving along its established track. Figures 2A-3 and 2A-4 show observed feminisation of both the judiciary and its main recruitment pool, law school graduates, and Appendix 3 gives the parametrisation for the judicial system of the 1980s.

Figures 8 through 11 suggest three findings. First, a one-shot purge in the 1990s would indeed have lowered the average age, and therefore the experience (and presumably quality) of judges, though the absolute drop in experience would not have been much greater than that which actually occurred by virtue of the near tripling of the number of judges between 1990 and 2005. Lustration would indeed have amounted to a human-resources shock but with limited long-term implications: the observed and counterfactual figures converge in roughly ten years. Second, a purge in 1990, even one preferentially targetting the higher levels, would have actually slowed down the rate of departures of socialist-era senior judges. This counter-intuitive behaviour emerges because the higher strata recruited almost exclusively from the layers immediately below, so a purge at the top would have pulled up many lowertier judges, who on average were younger. This would have re-stocked the higher courts not with fresh faces but with the youth wing of the old regime's cadres. The result would have been an even greater lingering of socialist-era judges than actually occurred. I call this demographic dynamic the "purge boomerang."

Finally, by comparing the slopes of Figure 2A-3 (observed judicial feminisation in the 1990s) and Figure 12 (counterfactual judicial feminisation had he 1980s/socialist system continued) we can see that feminisation of the higher level is largely linear in both cases. Markedly different, however, would have been the rate of feminisation of the lower tiers, which accelerated precipitously in the real world. Since most judges are at the low court, a perpetuation of the socialist system would have

39 During research visits to the archives of several Romanian courts I frequently observed that during the rapid judicial expansion of the early 1990s judicial positions associated with new local courts would often appear on the payroll several years before said positions were actually occupied by judges. This confirms both the independent existence of judicial positions and the difficulty in filling vacancies during a time of vertiginous system growth. 

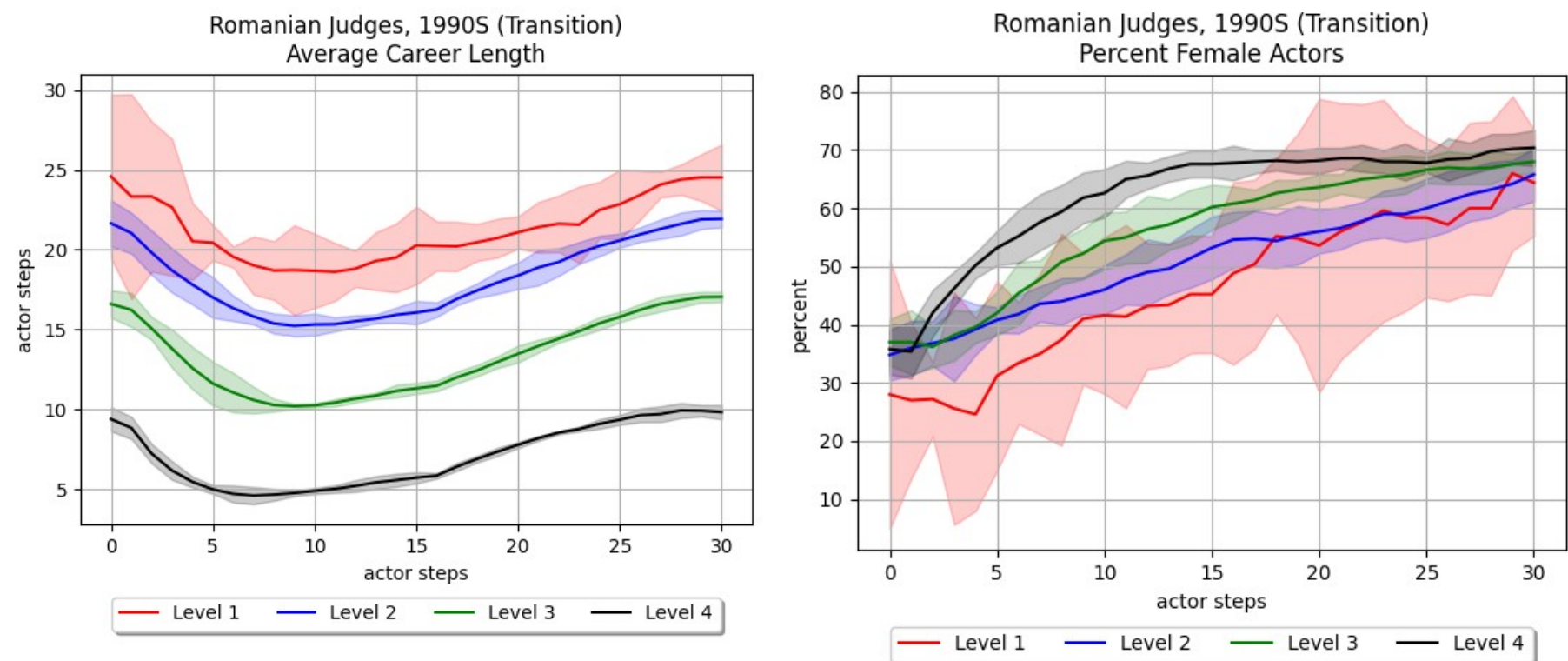

Figures 8 \& 9: Average career length and percent female from WCS model parametrised with average values of 1990s; disaggregated by level, where level 1 = High Court and Level $4=$ Local Court
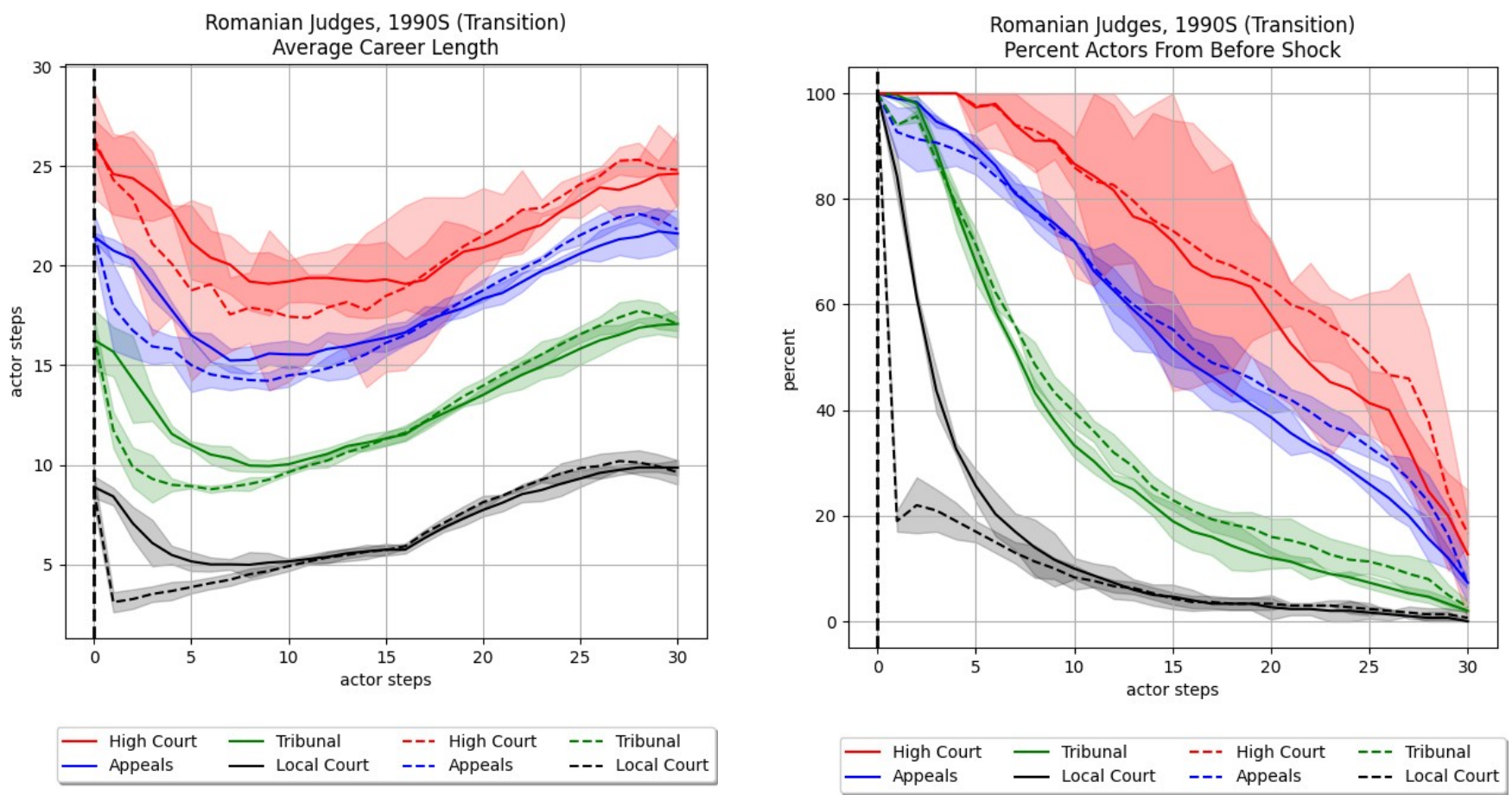

Figures 10 \& 11: Average career length and percent remaining before revolutionary shock (by judicial level), under observed (straight line) and counterfactual (dashed line) conditions. Shaded areas represent confidence bands two standard deviations wide. 


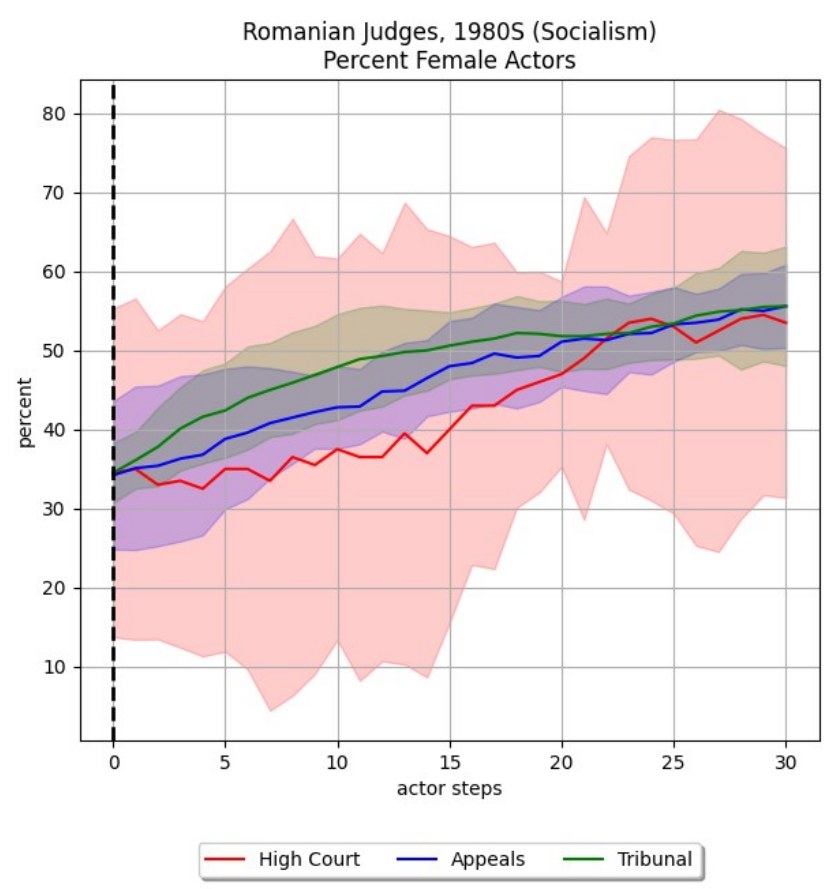

Figure 12: Evolution of percent female in the Romanian judiciary (by judicial level), had the system characteristics of the 1980's, socialist-era judicial system kept evolving after 1990.

entailed a less aggressive feminisation of the judiciary as a whole. This final counterfactual is undercut, however, by the fact that in the 1990s the feminisation of law school graduates also accelerated (see Figure 2A-4). Romanian judicial feminisation seems therefore to have been caused by a combination of demographic inertia (as judges from the more feminised low courts rose through the ranks), an accelerated cultural shift associating legal work with women (Ridgeway 2011), and system growth caused by a one-shot event, the December 1989 revolution. Each alone would have caused judicial feminisation, but together they compounded to create the nearly unheard-of situation in which the top tier of an elite profession is dominated by women.

\section{Conclusion}

The aim of this paper has been to advance the study of opportunity structures by providing a computational idiom in which to model vacancy processes. I introduced the White-Chase-Sørensen (WCS) model, justifying this approach on the grounds that it overcomes the limitations of analytic, Markov vacancy chain analysis (AM-VCA), which as of this writing is the canonical modelling paradigm for vacancy chain analysis.

More precisely, WCS models provide confidence bounds for point estimates, they lets us engage in pattern-oriented modelling (Grimm et al. 2005; Grimm and Railsback 2012), and they can relax canonical assumptions (like time embeddedness and actor homogeneity) which allows for greater realism, and they enable the study of dynamics and off-equilibrium systems. Theoretically, the combination of an evolving simulation with a Markov walks featuring absorbing states lets us recreate dynamic systems that nonetheless tend towards stability, such as ideal-typical bureaucracies. This is a very useful feature of WCS models, since organisations, housing markets, and systems of expert labour (i.e. professions) are in a constant and uneven tug-of-war between stasis and change, where stasis has 
the upper hand. Further, WCS models let us layer multiple processes. It was commonplace during the tumultuous $20^{\text {th }}$ century for entire occupations to experience tidal shocks, such as mass purges, rapid expansion, or professional feminisation. WCS models can incorporate such dynamics, and more besides.

There remain shortcomings with the WCS model, suggesting avenues for further development. First, WCS models assume that mobility is a single-mechanism affair exclusively involving vacancy chains. The multi-mechanistic nature of mobility in closed position systems was acknowledged and addressed in both the foundational text of VCA (White 1970, Part II) and in subsequent research Stewman (1988): future WCS work would do well to incorporate these dynamics. On a micro level, WCS models ignore both why actors retire and the process whereby vacant positions are filled, replacing what is usually a complex selection process-such as a tournament (Lazear and Rosen 1981)with random chance. Finally, the WCS approach does not endogenise position dynamics. Positions can reject potential occupants: some jobs are too important to be occupied by the wrong person. Moreover, positions may disappear not only by virtue of exogenous shocks but also as a matter of course: houses collapse, cars rust beyond repair, and separate jobs are combined. A rich model of vacancy dynamics should reflect the fact that closed position systems routinely shed and acquire positions.

One a more abstract level, WCS models represent a forward step for agent-based modelling as they are the first instance in which absence (here, vacancies) is formalised as a causal actor. For millennia learned men with an interest in counting resisted assigning a symbol to mark absence, as they considered it illogical (if not downright offensive) for something to mean nothing. The modern zero symbol spread primarily because well educated merchants like Fibonacci found zeros useful in accounting (Kaplan 1999). Likewise, vacancies qua absent actors are a practical concept that helps us better understand social mobility. A constant theme of this paper has been that a computational apprach can help vacancy chain analysis. It may be, however, that vacancies will fill the gap in agent-based models.

\section{Works Cited}

Abbott, Andrew Delano. 1988. The System of Professions: An Essay on the Division of Expert Labor. Chicago: University of Chicago Press.

Abbott, Andrew Delano, and D. Randall Smith. 1984. “Governmental Constraints and Labor Market Mobility: Turnover among College Athletic Personnel.” Work and Occupations 11(1):29-53.

Bianchi, Federico, and Flaminio Squazzoni. 2015. “Agent-Based Models in Sociology.” Wiley Interdisciplinary Reviews: Computational Statistics 7(4):284-306.

Breiger, Ronald L. 1974. “The Duality of Persons and Groups.” Social Forces 53(2):181-190.

Cartwright, Nancy. 1989. Nature’s Capacities and Their Measurement. Oxford: Clarendon Press.

Chase, Ivan D. 1991. “Vacancy Chains.” Annual Review of Sociology 17(1):133-154.

Collier, Andrew. 2001. “On Real and Nominal Absences.” Pp. 299-310 in After Postmodernism: An Introduction to Critical Realism, edited by J. Lopez and G. Potter. London and New York: Athlone Press. 
Crăcană, Iuliu. 2015. Dreptul în slujba puterii: justiția în regimul comunist din România, 1944-1958.

Bucureşti, Romania: Institutul Național pentru Studiul Totalitarismului.

Friman, H. Richard. 2004. "Forging the Vacancy Chain: Law Enforcement Efforts and Mobility in Criminal Economies.” Crime, Law and Social Change 41(1):53-77.

Grimm, Volker, Uta Berger, Finn Bastiansen, Sigrunn Eliassen, Vincent Ginot, Jarl Giske, John GossCustard, Tamara Grand, Simone K. Heinz, and Geir Huse. 2006. “A Standard Protocol for Describing Individual-Based and Agent-Based Models.” Ecological Modelling 198(1-2):115126.

Grimm, Volker, Uta Berger, Donald L. DeAngelis, J. Gary Polhill, Jarl Giske, and Steven F. Railsback. 2010. “The ODD Protocol: A Review and First Update.” Ecological Modelling 221(23):2760_ 2768.

Grimm, Volker, and Steven F. Railsback. 2012. “Pattern-Oriented Modelling: A ‘Multi-Scope’for Predictive Systems Ecology.” Philosophical Transactions of the Royal Society B: Biological Sciences 367(1586):298-310.

Grimm, Volker, Steven F. Railsback, Christian E. Vincenot, Uta Berger, Cara Gallagher, Donald L. DeAngelis, Bruce Edmonds, Jiaqi Ge, Jarl Giske, and Juergen Groeneveld. 2020. “The ODD Protocol for Describing Agent-Based and Other Simulation Models: A Second Update to Improve Clarity, Replication, and Structural Realism.” Journal of Artificial Societies and Social Simulation 23(2).

Grimm, Volker, Eloy Revilla, Uta Berger, Florian Jeltsch, Wolf M. Mooij, Steven F. Railsback, HansHermann Thulke, Jacob Weiner, Thorsten Wiegand, and Donald L. DeAngelis. 2005. "PatternOriented Modeling of Agent-Based Complex Systems: Lessons from Ecology.” Science 310(5750):987-991.

Hommes, Cars, and Blake LeBaron. 2018. "Introduction to the Handbook of Computational Economics, Volume 4, Heterogeneous Agent Modelling.” Pp. xxi-xxix in Hanbook of Computational Economics. Vol. 4, edited by C. Hommes and B. LeBaron. Amsterdam.

Ionescu, Mirel. 2016. Epurarea avocațiilor din Baroul Cluj. Cluj-Napoca, Romania: Argonaut.

Kaplan, Robert. 1999. The Nothing That Is: A Natural History of Zero. Oxford University Press.

Kristof, Frank S. 1965. "Housing Policy Goals and the Turnover of Housing.” Journal of the American Institute of Planners 31(3):232-45. doi: 10.1080/01944366508978170.

Lazear, Edward P., and Sherwin Rosen. 1981. "Rank-Order Tournaments as Optimum Labor Contracts.” Journal of Political Economy 89(5):841-864.

Lupascu, Dan. 2009. “Consiliul Superior al Magistraturii Din Romania Dupa Un Secol de La Infiintare Editorial.” Pandectele Romane 2009(3):17-34. 
Macy, Michael W., and Robert Willer. 2002. "From Factors to Actors: Computational Sociology and Agent-Based Modeling.” Annual Review of Sociology 28(1):143-166.

de Marchi, Scott, and Scott E. Page. 2014. “Agent-Based Models.” Annual Review of Political Science $17: 1-20$.

Marullo, Sam. 1985. “Housing Opportunities and Vacancy Chains.” Urban Affairs Quarterly 20(3):364-388.

Montagnes, B. Pablo, and Stephane Wolton. 2019. "Mass Purges: Top-down Accountability in Autocracy.” American Political Science Review 113(4):1045-1059.

Morvan, Gildas. 2012. “Multi-Level Agent-Based Modeling-a Literature Survey.” ArXiv Preprint ArXiv:1205.0561.

Pârvulescu, Radu Andrei. 2021. “The Romanian Judicial Professions Database: An Open-Source Tool for Researching the Romanian Legal System.” Journal of Romanian Studies 3(1).

Porpora, Douglas V. 2015. Reconstructing Sociology: The Critical Realist Approach. Cambridge University Press.

Ridgeway, Cecilia L. 2011. Framed by Gender: How Gender Inequality Persists in the Modern World. Oxford University Press.

Rosenbaum, James E. 1979. “Tournament Mobility: Career Patterns in a Corporation.” Administrative Science Quarterly 220-241.

Sørensen, Aage B. 1979. “A Model and a Metric for the Analysis of the Intragenerational Status Attainment Process.” American Journal of Sociology 85(2):361-384.

Sørensen, Aage B. 1983. "Processes of Allocation to Open and Closed Positions in Social Structure." Zeitschrift Für Soziologie 12(3):203-24. doi: 10.1515/zfsoz-1983-0302.

Stan, Lavinia. 2012. "Witch-Hunt or Moral Rebirth? Romanian Parliamentary Debates on Lustration.” East European Politics and Societies 26(2):274-295.

Stan, Lavinia. 2013. Transitional Justice in Post-Communist Romania: The Politics of Memory. Cambridge, MA: Cambridge University Press.

Stewman, Shelby. 1975. “Two Markov Models of Open System Occupational Mobility: Underlying Conceptualizations and Empirical Tests.” American Sociological Review 40(3):298-321. doi: $10.2307 / 2094460$.

Stewman, Shelby. 1988. “Organizational Demography.” Annual Review of Sociology 14(1):173-202.

Stewman, Shelby, and Suresh L. Konda. 1983. "Careers and Organizational Labor Markets: Demographic Models of Organizational Behavior.” American Journal of Sociology 88(4):637685. 
Stewman, Shelby, and Kuang S. Yeh. 1991. "Structural Pathways and Switching Mechanisms for Individual Careers.” Research in Social Stratification and Mobility 10:133-168.

Vogel, Mary E. 1996. “The Negotiated Guilty Plea: Vacancies as an Alternative to the Caseload Pressure Explanation.” Journal of Mathematical Sociology 21(3):241-288.

Weber, Max. 1978. “The Development of Bureaucracy and Its Relation to Law.” Pp. 341-54 in Max Weber: Selections in Translation, edited by W. G. Runciman. Cambridge, MA: Cambridge University Press.

White, Harrison C. 1970. Chains of Opportunity: System Models of Mobility in Organizations. Cambridge, MA: Harvard University Press.

White, Harrison C. 1971. "Multipliers, Vacancy Chains, and Filtering in Housing.” Journal of the American Institute of Planners 37(2):88-94. doi: 10.1080/01944367108977362.

Winters, Jeffrey A. 2011. Oligarchy. Cambridge, UK: Cambridge University Press.

Yamagata, Hisashi, Kuang S. Yeh, Shelby Stewman, and Hiroko Dodge. 1997. “Sex Segregation and Glass Ceilings: A Comparative Statics Model of Women's Career Opportunities in the Federal Government over a Quarter Century.” American Journal of Sociology 103(3):566-632. 


\section{Appendix 1: The ODD Protocol}

\section{$\underline{\text { Purposes and patterns }}$}

The purpose of the White-Chase-Sørensen (WCS) model is to understand how exogenous shocks affect mobility in closed position systems, ultimately affecting such outcomes as vacancy chain length, the length of actor careers, or the distribution of attributes in the population of actors. As the WCS model is novel there is not yet an established set of patterns that WCS implementations should be expected to generate. Nonetheless, since the WCS model aims to build upon analytic, Markov vacancy chain analysis (AM-VCA), we would expect WCS to reproduce certain patterns implied by AM-VCA. I therefore evaluate the WCS model by its ability to generate the following three theoretically-informed patterns.

Pattern 1: Approximate time-embedding of vacancy mobility. A vacancy chain should start and end within the time frame of observation. For example, in studies of organisations the time frame/unit is typically one year. That said, it might be expected (but not necessary) for chains to span two or three periods immediately after system shocks that introduce a large amount of vacancies. For example, some positions might remain empty for one or two years after a rapid burst of organisational expansion, a reality that the model should accommodate.

Pattern 2: Finitude of cohort effects. Cohort effects, for example the average experience of actors, measured in years, should eventually disappear as members of the cohort leave the system. For example, while a large entry cohort of actors may temporarily lower the average age of all actors across the organisation, as time passes the average age should stabilise. More generally, system shocks affecting cohorts should not propagate indefinitely, with the obvious exception of shocks affecting the system's structure, such as the permanent abolition of one hierarchical level.

Pattern 3: Convergence of the mean of stationary distributions to AM-VCA results. After a certain burn-in period and in the absence of any system changes or shocks, means of distributions generated by the WCS model should closely approximate closed-form results from AM-VCA, especially when we average across post-burn-in steps and/or across numerous WCS model runs. This expectation is due to the fact that WCS models are Monte Carlo simulations of AM-VCA walks.

Entities, state variables, and scales

Entities. This model includes the following entities: agents (representing actors and positions), positions (representing resource units, e.g. jobs, houses), hierarchical levels (i.e. ranked groups of positions), active and retired groups (recording whether or not an actor, vacancy, or position is still in the system) and the global environment, representing the organisation and its context (e.g. the number of levels, whether a system grows over time).

Actors represent tangible entities, such as humans or hermit crabs, that can occupy vacant positions and retire, thereby introducing vacancies into the system. Vacancies represent absences that can occupy positions, can swap positions with an actor (causing intra-system mobility), and can retire, thereby recruiting new actors into the system. Positions are resource units that must always be occupied by either an actor or a vacancy. Hierarchical levels are ranked groups of positions, often comprising a pyramid: the presence of an actor or vacancy in a particular level determines the probability with which 
that entity retires or moves within-system, as the case may be. ${ }^{40}$ Active vs. retired groups record whether or not an actor or vacancy is still in the system and therefore liable to act and be acted upon. The global environment defines the characteristics of the closed positions system, such as the distribution of positions across levels, as well as exogenous trends, such as the rate of system growth or the timing of major system downsizing.

State Variables. Table A1-1 presents the state variables associated with actors, vacancies, and positions, and Table A1-2 presents the state variables associated with the global environment. Hierarchical levels and active/retired groups implicitly arise from system parameters and agent interaction (see below, Design Concept: Collectives), and therefore do not have state variables.

\begin{tabular}{|c|c|c|c|}
\hline $\begin{array}{l}\text { Variable } \\
\text { Name }\end{array}$ & Entity & $\begin{array}{l}\text { Variable Type and } \\
\text { Unit }\end{array}$ & Meaning \\
\hline \multirow{2}{*}{ unique_id } & Position & $\begin{array}{l}\text { Static: text, in } \\
\text { format LEVEL- } \\
\text { SPOT }\end{array}$ & $\begin{array}{l}\text { A unique position ID. E.g. 4-12 means "level four, spot } \\
\text { twelve" }\end{array}$ \\
\hline & $\begin{array}{l}\text { Actor/ } \\
\text { Vacancy }\end{array}$ & $\begin{array}{l}\text { Static: a unique ID } \\
\text { object from Python's } \\
\text { uui4 module }\end{array}$ & A random, unique ID for actors and vacancies \\
\hline type & $\begin{array}{l}\text { Position, } \\
\text { Actor, } \\
\text { Vacancy }\end{array}$ & Static: text & “Actor”, "vacancy” or “position” \\
\hline \multirow[b]{2}{*}{$\log$} & Position & $\begin{array}{l}\text { Variable: a list of } \\
\text { uuid4 objects }\end{array}$ & $\begin{array}{l}\text { A list of the unique IDs of each actor that has ever } \\
\text { occupied this position, ending in the current actor- } \\
\text { occupant }\end{array}$ \\
\hline & $\begin{array}{l}\text { Actor, } \\
\text { Vacancy }\end{array}$ & $\begin{array}{l}\text { Variable: a list of } \\
\text { text }\end{array}$ & $\begin{array}{l}\text { A list of the unique IDs of each position that this actor/ } \\
\text { vacancy has ever occupied, ending in the current } \\
\text { position, e.g. [“4-12”, “4-9”, “3-2"]. After retirement } \\
\text { the lost entry of the log is the last position. }\end{array}$ \\
\hline position & $\begin{array}{l}\text { Actor/ } \\
\text { Vacancy }\end{array}$ & Variable: text & $\begin{array}{l}\text { The unique id of the position that the actor/vacancy is } \\
\text { currently occupying }\end{array}$ \\
\hline occupant & Position & $\begin{array}{l}\text { Variable: set with } \\
\text { uuid4 object, text, } \\
\text { and a boolean (i.e. } \\
\text { True/False) }\end{array}$ & $\begin{array}{l}\text { A set containing three pieces of information: the unique } \\
\text { ID of the actor/vacancy currently occupying this } \\
\text { position; the type of the current occupant (i.e. "actor" } \\
\text { or "vacancy); and whether or not an actor has already } \\
\text { moved into this position during the current actor step }\end{array}$ \\
\hline
\end{tabular}

40 Note the difference between the implicit but hard-coded hierarchical levels of WCS models and the emergent and fuzzy levels of multi-level agent-based models are the closest analogue (Morvan 2012). I did not leverage the latter to study mobility in closed position systems because in multi-level ABMs positions are either implicit or emergent, which does not align with VCA's theoretical assumption that positions are distinct and objective entities whose existence does not simply "emerge" out of agent interaction (White 1970:1). Relatedly, using multi-level ABMs to model vacancy chains would be awkward because in such models the book-keeping is done at the agent or group levels, while VCA is centrally concerned with the distinct positions through which vacancies or actors pass. 
Table A1-1: State variables for actors, vacancies, and positions.

\begin{tabular}{|c|c|c|}
\hline Variable Name & Variable Type and Unit & Meaning \\
\hline positions_per_level & List of integers & $\begin{array}{l}\text { The distribution of positions across hierarchical } \\
\text { levels. }\end{array}$ \\
\hline actor_retire_probs & $\begin{array}{l}\text { List of fractions, } \\
\text { each on }[0,1]\end{array}$ & $\begin{array}{l}\text { The probability that an actor in a certain level will } \\
\text { retire during an actor step. }\end{array}$ \\
\hline vac_trans_prob_mat & $\begin{array}{l}\text { Matrix of fractions, each on } \\
\text { on }[0,1]\end{array}$ & $\begin{array}{l}\text { A matrix of transition probabilities for vacancies, } \\
\text { which defines the Markov walk. }\end{array}$ \\
\hline dismissal_schedule & $\begin{array}{l}\text { Set of actor step numbers } \\
\text { (integers), where each step } \\
\text { is associated with a list of } \\
\text { fractions, each on }[0,1]\end{array}$ & $\begin{array}{l}\text { A set of actor steps, where each step is associated } \\
\text { with retirement probabilities for actors during that } \\
\text { step only. }\end{array}$ \\
\hline growth_orders & $\begin{array}{l}\text { Set of actor step numbers } \\
\text { (integers), where each step } \\
\text { is associated with a list of } \\
\text { integers }\end{array}$ & $\begin{array}{l}\text { A set of actor steps, where each step is associated } \\
\text { with a cross-level distribution of positions to add } \\
\text { to the system during that step. }\end{array}$ \\
\hline shrink_orders & $\begin{array}{l}\text { Set of actor step numbers } \\
\text { (integers), where each step } \\
\text { is associated with a list of } \\
\text { integers }\end{array}$ & $\begin{array}{l}\text { A set of actor steps, where each step is associated } \\
\text { with a cross-level distribution of positions to } \\
\text { remove from the system during that step. }\end{array}$ \\
\hline level_addition & $\begin{array}{l}\text { Set containing: an actor step } \\
\text { (integer), a level rank } \\
\text { (integer), a number of } \\
\text { positions (integer), a list of } \\
\text { fractions, a matrix of } \\
\text { fractions }\end{array}$ & $\begin{array}{l}\text { Indicates the actor step at which we add a } \\
\text { hierarchical level, tells us where that level should } \\
\text { rank in the new hierarchy, tells us how many } \\
\text { positions should be in that new level, and supplies } \\
\text { new actor retirement probabilities and new } \\
\text { vacancy transition probabilities }\end{array}$ \\
\hline level_removal & $\begin{array}{l}\text { Set containing: an actor step } \\
\text { (integer), a level rank } \\
\text { (integer), a list of fractions, } \\
\text { a matrix of fractions }\end{array}$ & $\begin{array}{l}\text { Indicates the actor step at which we remove a } \\
\text { hierarchical level, tells us which level (by rank) to } \\
\text { remove, and supplies new actor retirement } \\
\text { probabilities and new vacancy transition } \\
\text { probabilities }\end{array}$ \\
\hline start_fract_attr & A fraction on $[0,1]$ & $\begin{array}{l}\text { Indicates what percent of the starting population } \\
\text { of actors should have the generic attribute. }\end{array}$ \\
\hline prob_attr_per_step & A fraction on $[0,1]$ & $\begin{array}{l}\text { Indicates the probability that a newly recruited } \\
\text { actor will have the generic attribute }\end{array}$ \\
\hline vac_ben_def_mat & A matrix of real numbers & $\begin{array}{l}\text { Indicates the cost/benefit associated with each } \\
\text { possible within-system vacancy move. }\end{array}$ \\
\hline vac_move_period & An integer & $\begin{array}{l}\text { The number of model ticks between actor steps } \\
\text { during which a vacancy can move }\end{array}$ \\
\hline
\end{tabular}

Table A1-2: State variables for the global environment. 
Scales. The spatial dimension is a hierarchy, with the property that all positions within the same hierarchical level are equally distant both from one another and from positions in other levels. Moreover, the relative ease of moving within and among levels is decided partly by the system-level vacancy probability matrix, and partly by the total number of vacancies currently in the system (see Submodels, Vacancy Movement below). Therefore there is no absolute concept of spatial scale in the model: what "close" means to an agent depends on their current level, the vacancy transition probability matrix, and the relative preponderance of vacancies in the system.

\section{Process Overview and Scheduling}

For a visual representation of the process, see Figure 2 above. There are three temporal dimensions within the model: model ticks, vacancy move periods, and actor steps. The model ticks are each discrete step of the simulation. The vacancy move period is defined as the number of ticks between actor steps: it is only during these periods that vacancies can move. Finally, actor steps separate vacancy move periods, at regular intervals: actors can only retire during these steps, and they can only move once between actor steps. To give an example, suppose that we run the model for fifty ticks, setting the vacancy move period to be nine ticks long, and for actor steps to occur every tenth tick. The successive vacancy move periods will comprise the tick intervals 1-9, 11-19, 21-29, 31-39, and 41-49; and the actor steps will fall on model ticks 0, 10, 20, 30, 40, and 50.

Only the actor steps are interpreted in terms of natural time: in studies of organisations, for example, actor steps are naturally interpreted as years. This implies that actor mobility is not embedded in a Markovian sense. On the other hand, the size of the vacancy move period determines the extent to which vacancy chains play out between actor steps. The larger the vacancy move period, the more likely it is that a vacancy chain starts and ends in the same period, and therefore the more that the vacancy walk approximates an embedded Markov chain.

Bringing it all together, at the beginning of the typical actor step there are no vacancies in the system. Before any agent moves we run the data collectors, refresh the lists of retirees (so that they are empty again), and reset to "False” each position's boolean value indicating whether an actor has moved in that position during this actor step. Then, if this actor step features system growth/shrinking, the addition/removal of a level, or a spate of dismissals, we carry it out. Finally, the actors choose, independently and in random order, whether or not to retire: those that do retire leave the active group, enter the retired group, and bring vacancies into their old positions. The actor step ends by updating each position's log. Then begins the vacancy move period.

During each model tick in the vacancy move period, each vacancy moves (in random order) according to the global vacancy transition probability matrix. Whenever a vacancy retires it leaves the active group, enters the retirement group, and recruits a new actor. When a vacancy moves withinsystem it swaps positions with an actor. If a vacancy cannot find a suitable positions to which to move the vacancy forfeits its mobility for that model tick, and waits for the next tick to try again. These vacancy movements continue until the end of the vacancy move period, after which the next actor step begins and the process repeats, until the end of the model. If any vacancies survive the end of the vacancy more period they remain inert during the actor step, after which point they reactivate.

\section{Design Concepts}

Basic principles. The WCS model computationally simulates the classic vacancy chain process in which actor mobility only occurs in the presence of a vacancy. In this framework vacancies are both 
necessary and sufficient for movement, with the consequence that vacancies are the principal mechanism of mobility. At the same time, this model differs from AM-VCA by endogenising vacancy creation in the form of actor retirement: vacancies determine movement, but actors determine the presence of vacancies. The WCS model expresses the theoretical expectation that systems of closed positions always tend towards dynamic equilibria and are incapable of endogenous evolution (see more in Stochasticity below). At the same time, these systems are routinely subject to exogenous influences, whether as gradual changes (e.g. system growth over twenty years) or sudden shocks (e.g. a purge wherein half of the actors are fired). Consequently, the main focus of the WCS model is on the metainteraction of three factors: the model's equilibrating tendency, the effects of exogenous shocks, and the particular structure of the closed position system, e.g. the extent to which vacancies in the $\mathrm{n}^{\text {th }}$ level always go to actors in level n-1 (that is, the strictness of seniority rules of promotion).

Emergence. All WCS model patterns emerge out of the interaction of vacancies and actors, as mediated by system parameters, the relative preponderance of vacancies, and interactional constraints (more on these constraints in Submodels below). For example, the extent to which the model approximates vacancy embeddedness depends on a system parameter (the length of the vacancy move period), the density of vacancies within system, and interactional constraints: vacancies cannot move to already-vacant positions, so the more vacancies there are the less they can move, and the longer they take to leave the system. Generally speaking, results emerge out of the stochastic movement of actors and vacancies within a highly structured system whose parameters are exogenously determined.

Sensing. Actors and vacancies are assumed to be able to read off their system-level retirement and mobility probabilities, as the case may be. Moreover, a vacancy is assumed to be able to sense a) the type of actor occupying the position to which said vacancy wants to move, and b) whether the desired position has already featured actor movement in the current actor step.

Interaction. Interaction occurs both directly and indirectly. In the first case, actors and vacancies directly swap positions with one another; note that when an agent retire they "swap" positions with a dissimilar recruit, e.g. a retiring actor "swaps" positions with an extra-system vacancy. In the second case, vacancies indirectly constrain each others' movement by virtue of the fact that a) vacancies cannot occupy already-vacant positions, and b) vacancies cannot swap with an actor that another vacancy has already moved in this turn. Technically, indirect constraints are mediated by positions (see Submodels below).

Stochasticity. Stochasticity occurs in the movement of actors and vacancies, both of which use a probability distribution to decide whether to retire or move in system, as the case may be.

Collectives. The two kinds of groups are hierarchical levels and active/retired groups. Hierarchical levels are implicit in positions' ID's and in the vacancy probability transition matrix. The active group is simply the set actors/vacancies currently within the system and therefore liable to move, while the retired group is the set of actors/vacancies that were at one point in the system, but now no longer are, and are therefore inert.

Observation. The WCS model generates both numeric and graphical output. The numeric output refers to the first and second moments (mean and standard deviation) of distributions of interest after throwing out the burn-in period, implying that the underlying distributions are stationary. Graphical 
output shows time series of these moments as they evolve across actor steps, the purpose of which is to aid in discerning the system's off-equilibrium dynamics.

$\underline{\text { Initialisation }}$

The system's size, the distribution of positions across hierarchical levels, the actors' retirement probabilities, the vacancy transition probability matrix (which includes probabilities for transitions to the "outside," i.e. vacancy retirement), the starting fraction of the population endowed with the generic attribute, the per-actor-step probability that newly recruited actors will share said attribute, and the vacancy move period are all required to initialise the model. There are no default values for these system-level state variables, and they must be supplied by the model user. See Figure 3 for a schematic example of initialisation values.

All positions are initially occupied by actors, i.e. the system begins with no vacancies. Moreover, at start-up all positions and actors have only one value in their logs, namely their initial actor/position dual.

Input

There are six system-wide state variables that the user may optionally define: vac_ben_def_mat, dismissal_schedule, growth_orders, shrink_orders, level_addition, and level_removal. These first variable associates vacancy transitions with numeric benefits of deficits, while the subsequent five variables refer to exogenous changes that the system suffers, either due to slow development (e.g. the Michigan state police continuously grew in size between 1919 and 1969, [Stewman 1975]) or sudden shock (e.g. the communist-led purge of lawyers in post-WW2 Romania [Ionescu 2016]). In either case the magnitude of these variables is given by historical data, the secondary literature, and/or theoretically interesting scenarios, for instance counterfactuals such as "how would the average experience of actors have evolved had the system not grown?” An example initialisation can be found in Figure 4.

\section{$\underline{\text { Submodels }}$}

The first two submodels refer to actor and vacancy movement of two kinds, within-system recruitment and retirement, the latter implying recruitment of a new, dissimilar entity. The last three submodels refer to five ways in which a system can (exogenously). Referring to the first two submodels, note that both retirement and within-system movement probabilities differ by hierarchical level, so that actors and vacancies at different levels may (and usually do) have different mobility probabilities. With regards to mobility, however, all actors/vacancies are the same, since the WCS model specifies actor and vacancy transition probabilities system-wide: for instance, at any given actor step all actors in the same level share a retirement probability. This enforces per-level entity homogeneity with respect to mobility; actors may of course differ in virtue of having different ascribed characteristics.

Actor/Vacancy Retirement. At each type-specific step the actor/vacancy has the opportunity to retire, according to the system-wide retirement probabilities supplied to the model. Additionally, actors have a lifespan at the end of which they must leave the system. When an actor/vacancy retires they leave the active set where mobility is possible and enter the retired set, which freezes the entity's variables in their final state before retirement. Upon retirement, the retiring entity "recruits” a new, dissimilar entity to fill their old spot: actors recruit vacancies, and vacancies recruit actors. Technically, new recruit 
entities are created at the moment of recruitment, to avoid burdening computer memory with entities that may never be used. Furthermore, when entities retire they do so permanently: there is no chance to return to the system after retirement. Note that retirement-recruitment decisions are entirely independent, being determined solely by the system-wide, entity-specific retirement probabilities. All told, this submodel endogenises vacancy creation and actor recruitment and therefore adds dynamism to the AM-VCA model.

Vacancy Movement. At each model tick during a vacancy move period, a vacancy will select a level to which to move according to the transition probability vector associated with its current level, which is one row of the system-wide transition probability matrix. The information in this vector is of the form "move to level one with probability $a$, move to level two with probability $b$, retire with probability $c$," where $a+b+c=1$. If the vacancy uses this probability vector to move within-in system (i.e. it chooses a certain level, not retirement), the vacancy randomly picks five positions within the destination level and checks each position for suitability. The first time it finds a suitable position, the vacancy swaps positions with the actor currently occupying said position: for example, a vacancy moving down one level necessarily implies an actor moving up a level. This codes in both the symmetry requirement of vacancy movement and the notion that vacancies not only have the causal initiative in terms of withinsystem movement, but are both necessary and sufficient to effect such mobility (see Vacancy Competition and Closed Position Systems above). ${ }^{41}$

However, a vacancy move may fail because none of the five randomly selected candidate positions in the destination level are suitable. First, vacancies may not move to an already-vacant position, since a "double vacancy" is nonsensical. Second, actors may not move more than once per actor step, which mirrors methodological best practice of selecting a window of observation that lasts as long as the basic event under study. ${ }^{42}$ Operationally, when a vacancy move fails (i.e. the vacancy picked a new level but could not find a suitable positions) the vacancy in question forfeits its tun, which equals one model tick during the vacancy move period. At the next within-vacancy-period tick the vacancy tries to move again, and this process repeats until the vacancy retires.

These constraints create the opportunity for an approximate actualisation of vacancy embeddedness. When there are many vacancies (e.g. due to a wave of actor retirements) each vacancy has fewer places to go, both because more positions are already occupied by vacancies and because more actors will have been moved by the surfeit of vacancies. Therefore, a vacancy may be unlucky in finding suitable positions and successively forfeit its turns until the vacancy move period ends, at which point the vacancy rolls over into the next vacancy mover period. All else equal, the shorter the vacancy move period or the higher the proportion of vacancies relative to actors the more likely it will be that a vacancy spans two or more vacancy move periods, thereby increasingly violating the vacancy embedding assumption.

Dismissals. At any given actor step, or at multiple actor steps, we may tell the system to "fire" occupants in different hierarchical levels. Note that in so doing we do not literally remove a certain proportion of actors from their positions, but rather change actors' retirement probabilities for that actor step only. For example, if under normal circumstances each actor in the top level has a ten percent probability of retirement, if we try to fire half of the top-level actors in actor step $t$ then the

41 I am indebted to Abbott (1988:88-89) for the insight that in VCA vacancies are both necessary and sufficient for mobility.

42 In human closed position systems the time window is often socially relevant: students in modern schools change grades once a year, and promotions in bureaucracies follow an annual review. Consequently, the window of observation is one year, the actor step is also one year, and the indirect constrain is interpreted as "actors can only move once per year." 
probability of retirement of each top-level actor will become 0.5 for actor step $t$ only. This creates stochastic noise, which diminishes with growth in the number of actors in the targetted level and/or an increase in the number of model iterations across which we average. This "noisy" firing via retirement probabilities, as opposed to simply vacating a certain fraction of actor-occupied positions in a particular level, is meant to replicate empirical instances of mass firing, even political purges, which frequently operate through actors and not merely on them (Crăcană 2015; Montagnes and Wolton 2019). As the number of model iterations across which we average increases, however, the firing increasingly resembles a mechanical purge in which a proportion of actors will with be summarily dismissed with certainty. Evidently, when actors retire they bring in vacancies, so a mass firing introduces a mass cohort of vacancies.

System Expansion/Contraction. At any given actor step, or at multiple actor steps, we may increase or decrease the number of positions in different hierarchical levels, without however altering the number of levels; such changes are permanent. Newly added positions begin vacant, with the implication that system expansion introduces a cohort of vacancies. On the other hand, when a position is removed its current occupant (either an actor or a vacancy) is forcibly retired with no recruit or replacement brought in, since this latter would have nowhere to go.

Adding/Removing Hierarchical Levels. Once per simulation, we may either add or remove a hierarchical level, which triggers additions or removals of positions that precisely follow the mechanics discussed in System Expansion/Contraction; such changes are permanent. When adding/removing levels we alter the architecture of the system, and must therefore specify new actor retirement probabilities and a new vacancy transition probability matrix. If we are measuring benefits/deficits of vacancy transitions, we must also specify a new vacancy benefit/deficit transition table, and any further exogenous changes imposed on the system (e.g. mass firings) must take into account the system's current architecture at the time of the change. 
Appendix 2: Demographic Variation in Romanian Judiciary, 1978-2018

These data come from the Romanian Judicial Professions Database (Pârvulescu 2021).

\begin{tabular}{|l|l|l|l|l|l|}
\hline Judicial Level / Year & $\mathbf{1 9 8 8}$ & $\mathbf{1 9 8 9}$ & $\mathbf{1 9 9 0}$ & $\mathbf{1 9 9 1}$ & $\mathbf{1 9 9 2}$ \\
\hline High Court & 0.0 & 0.7 & 0.0 & 0.05 & 0.05 \\
\hline County Tribunal & 0.03 & 0.08 & 0.08 & 0.03 & 0.03 \\
\hline Low Court & 0.02 & 0.04 & 0.05 & 0.04 & 0.05 \\
\hline
\end{tabular}

Table A2-1: Yearly observed retirement probability per judicial level, estimated from a sample of Romanian judges representative of both geographic areas and judicial levels.

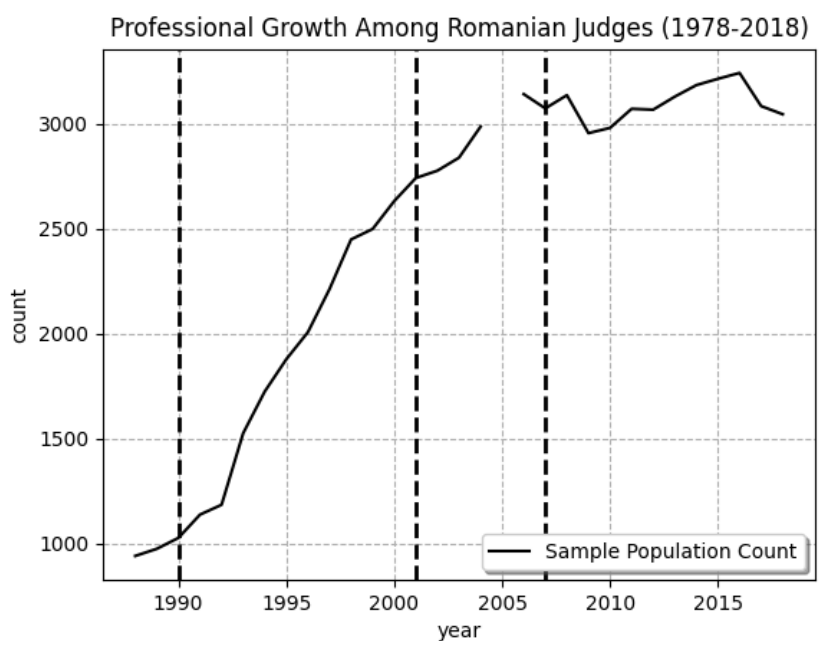

Figure A2-1: Growth of the Romanian judiciary, from a sample representative of both geographic areas and judicial $j$ levels. The dashed lines mark years of judicial reforms.

Yearly Percentage of Female Judges (1978-2018)

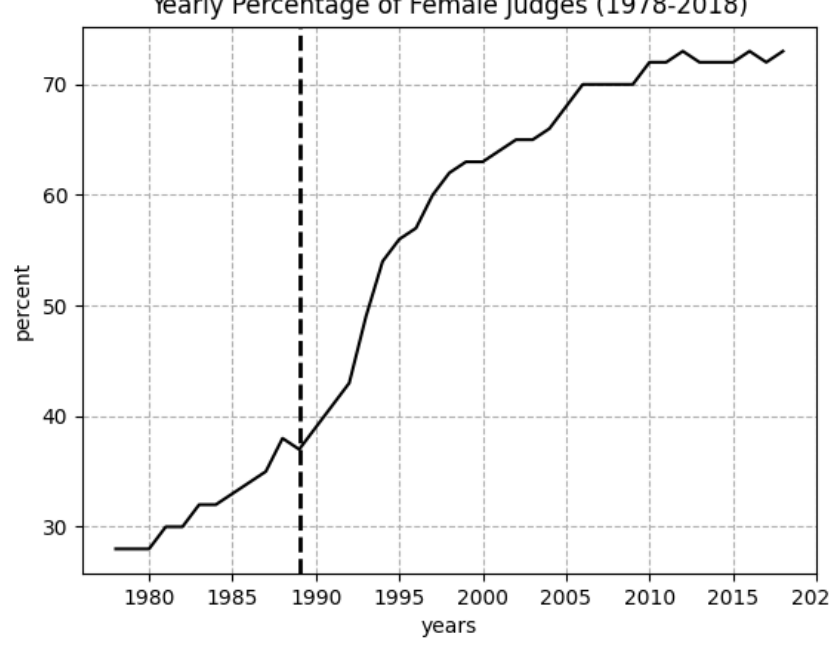

Figure A2-3: Yearly percentage of female judges, out of total judiciary, from a sample of judges representative of both geographic areas and judicial levels. The dashed line marks the anti-communist revolution in December of 1989.

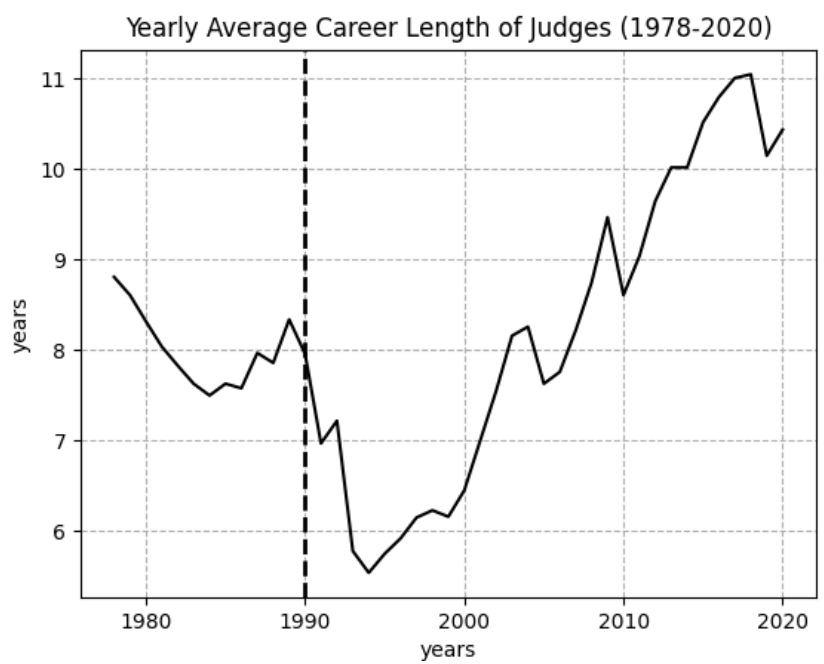

Figure A2-2: Yearly average career length, from a sample of judges representative of both geographic areas and judicial levels The dashed line marks the end of communism in 1990.

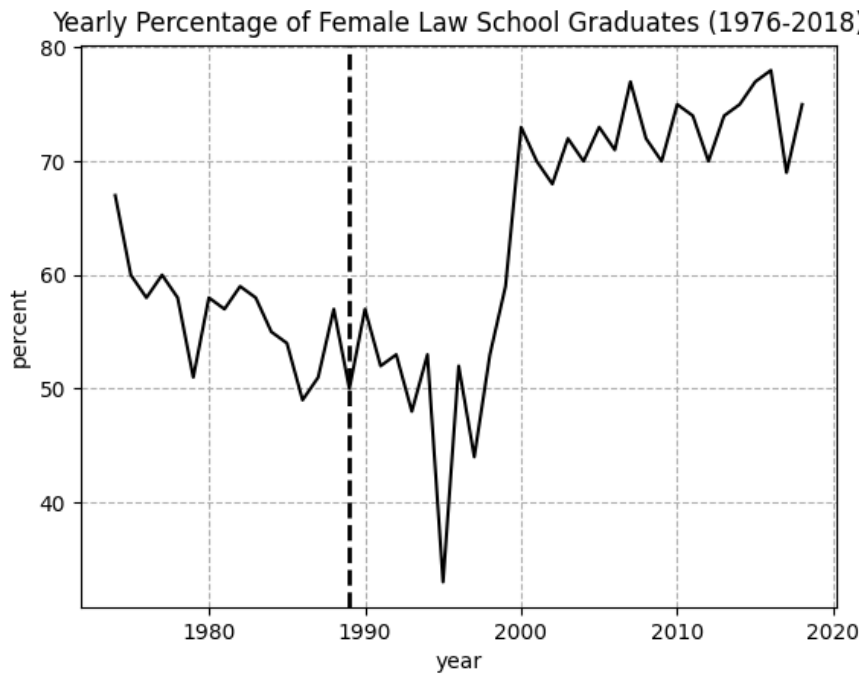

Figure A2-4: Yearly percentage of female law school graduates, from a sample of two of Romania's three historic law schools, those in the cities of Cluj and Iaşi. The dashed line marks the end of communism in 1990. 


\section{Appendix 3: Parametrisation of the Baseline and Counterfactual Models}

The 1990s Transition

Burn-in steps: 40

Actors Steps: 70

Inter-step (i.e. vacancy) period: 30

Total Simulation Steps: 2101

Size of System: High Court - 20; Appeals - 200; Tribunal - 300; Local Court - 400

Actor Retirement Probabilities: High Court - 0.1; Appeals - 0.02; Tribunal - 0.05; Local Court - 0.02

Vacancy Transition Probability Matrix:

\begin{tabular}{|l|l|l|l|l|l|}
\hline & High Court & Appeals & Tribunal & Local Court & Outside \\
\hline High Court & 0 & 1 & 0 & 0 & 0 \\
\hline Appeals & 0 & .01 & 0.84 & 0.06 & 0.09 \\
\hline Tribunal & 0 & 0 & 0.26 & 0.71 & 0.03 \\
\hline Local Court & 0 & 0 & 0.04 & 0.22 & 0.74 \\
\hline
\end{tabular}

Growth Orders: Increase each level by 10\% for 15 steps, starting at step 40.

Percent female actors at model initialisation: 35\%

Initial probability that newly recruited actors are female: 0.55

Feminisation orders: Increase probability that newly recruited actors will be female from 0.55 to 0.7 over ten steps, starting at step 40.

Counterfactual condition - Firing Orders: Only for step 40 change the actor retirement periods to

High Court - 0.6; Appeals - 0.5; Tribunal - 0.4; Local Court - 0.3

The 1980s, Socialism

Burn-in steps: 40

Actors Steps: 70

Inter-step (i.e. vacancy) period: 30

Total Simulation Steps: 2101 
Size of System: High Court - 20; Tribunal - 200; Local Court - 400

Actor Retirement Probabilities: High Court - 0.1; Tribunal - 0.05; Local Court - 0.02

Vacancy Transition Probability Matrix:

\begin{tabular}{|l|l|l|l|l|}
\hline & High Court & Tribunal & Local Court & Outside \\
\hline High Court & 0 & 0.83 & 0 & 0.17 \\
\hline Tribunal & 0 & 0.19 & 0.59 & 0.22 \\
\hline Local Court & 0 & 0.03 & 0.32 & 0.65 \\
\hline
\end{tabular}

Percent female actors at model initialisation: 35\%

Initial probability that newly recruited actors are female: 0.55 